Schlüsse zu ziehen. Das Protoplasma dieser Zellen übernimmt den Farbstoff gleich demjenigen anderer Zellen des Tierorganismus leicht und schnell aus dem Blut des mütterlichen Sinus und entfernt ihn ebenso schnell aus dem Körper, wobei derselbe in das Blut des fötalen Gefäßsystems übergeführt wird. Die Summe der beobachteten Tatsachen zeigt, daß die physiologischen Prozesse, an denen die Lebensfähigkeit dieser Zellen beteiligt ist, ganz normal fortschreiten, daß also eine spezifische Funktionsstörung dieser Zellen nicht eintritt und der Biochemismus derselben sich nicht ändert.

Im allgemeinen kann ich erwähnen, daß einige Farbstoffe in den Embryo nicht übergehen, im Protoplasma der begrenzenden Ektodermzellen der Plazenta festgehalten werden und keine pathologisch-chemischen Veränderungen in den letzteren hervorrufen. Andere Farbstoffe gehen sehr leicht in den Organismus des Embryo über, fügen seiner Entwicklung keinen Schaden zu und rufen keine pathologischchemischen Veränderungen im Protoplasma der begrenzenden Ektodermzellen der Plazenta hervor. Die dritte Gruppe endlich bilden diejenigen Farbstoffe, welche teilweise in den Organismus des Embryo übergehen, aber nur nachdem sie pathologisch-chemische Veränderungen im Protoplasma der begrenzenden Ektodermzellen der Plazenta hervorgerufen haben. Sie erweisen sich als schädlich für die Entwicklung des Embryos, während die ersten beiden Farbstoffgruppen durch eine fast völlige oder absolute Unschädlichkeit für den Tierorganismus charakterisiert sind.

Es liegt nahe, daß wenn wir von einer schützenden Kraft des biologischen Filters, das von der Natur an der Grenze des Gefäßsystems zwischen Mutter und Embryo geschaffen ist, sprechen, wir dieselbe in den chemischen Eigenschaften derjenigen protoplasmatischen Elemente zu suchen haben, die sich unserem Auge in Form von gefärbten Körnchen bei Anwendung der Methode der vitalen Färbung darstellen.

\title{
IV. \\ Systematische Lichtungs- und Dickenmessungen der großen Arterien und ihre Bedeutung für die Pathologie der Gefäßse.
}

(Aus dem Pathologischen Institute der Universität München.)

Von

I wa ki chi Kani aus Morioka (Japan). (Mit 1 Textfigur.)

Seitdem von Vir chow die Enge der Aorta in ätiologischen Zusammenhang mit Chlorose, Hämophilie und andern Blutkrankheiten gebracht worden ist, hat diese Anomalie in der Pathologie eine große Rolle gespielt. Während Vir - 
c how selbst sehr häufig ,,enge Aorta“" diagnostizierte, sind z. B. S u t e r und S c h e e l der Ansicht, daß sie überhaupt nicht vorkomme. Und diese Kontroverse, deren stärkste Gegensätze eben angedeutet wurden, besteht auch noch heute.

Um hier Klarheit zu schaffen, sind von mehreren Autoren Messungen vorgenommen worden. Von der Vermutung ausgehend, daß die enge Aorta nur Teilerscheinung einer Hypoplasie des gesamten Arteriensystems sei, erweiterte man die Untersuchungen auf Messungen der Pulmonalis, Carotis und anderer Gefäße. Die wichtigsten Arbeiten auf diesem Gebiete stammen von $\mathrm{S}$ u t e $\mathrm{r}^{1}$, Beneke ${ }^{2}$, Sehiele-Wiegandt ${ }^{3}$ und Scheel ${ }^{4}$.

Alle diese Untersuchungen stimmen im großen ganzen darin überein, daß’der Umfang der Aorta und der großen Arterien von der Geburt bis in das höhere Alter allmählich zunimmt, daß die Maße für Männer höher sind als für Frauen derselben Altersklasse, und daß große Individuen im allgemeinen weitere Gefäße haben als kleine. Mit diesem von der Größe der Individuen abhängigen Unterschied im Kaliber der Arterien wird auch bisher der der Geschlechter in Zusammenhang gebracht. Innerhalb der einzelnen Altersklassen fanden sich aber auch andere sehr große Schwankungen der Gefäßweite ( $\mathrm{S}$ u te r, S cheel). Was das Verhalten der Wachstumsgeschwindigkeit der Aorta zu der der Pulmonalis betrifft, so fand $S$ c h e el in Úbereinstimmung mit andern Autoren, daB in der Jugend die Pulmonalis weiter ist als die Aorta ascendens, da $B$ aber später (bei Männern etwa im Alter von 40, bei Frauen von 50 Jahren) das umgekehrte Verhältnis eintritt. Abgesehen vom Wachstum glaubt B e n e k e, daß große Herzarbeit bei Herzhypertrophie auf die Weite des gesunden arteriellen Gefäßsystems gar keinen oder doch nur einen ganz unerheblichen Einfluß hat. Im Gegensatz hierzu behauptet $\mathrm{S}$ ch e el, daß jede pathologische oder physiologische Blutdrucksteigerung eine Ausdehnung der Gefäße bewirkt.

Während sich diese Autoren auf Umfangmessungen beschränken, stellte $\mathrm{S} \mathrm{ch}$ i e le - W i e g a n d t in etwas über 100 Fällen auch die Wanddicke fest. Er kam dabei zu dem Resultate, daß diese ebenso wie die. Weite bei Frauen geringer ist als bei Männern und in allen Arterien bei beiden Geschlechtern bis in das höhere Alter allmählich zunimmt. An pathologischen Befunden wies er nach, daß Individuen, die an perniziöser Anämie, Kachexie oder langwierigen Krankheiten litten, enge und dünnwandige Gefäße hatten.

Bei seinen Dickenmessungen bediente sich $S \mathrm{chiele}-\mathrm{W}$ iegandt zunächst des $\mathrm{Qu}$ inckeschen Hebelapparates. Diese Methode gestattete zwar eine rasche und verhältnismäßig einfache Ausführung der Messungen: das der Leiche entnommene Material kommt, frisch zwischen zwei Deckgläser von bekannter Dicke gebracht, unter den in einer Schneide endigenden kurzen Hebelarm zu liegen, die Ablesung erfolgt an einer vom langen Hebelarm bestrichenen Skala. Sie vermochte jedoch nur die Maximaldicke eines untersuchten Gefäßwandstückes zu bestimmen und zeitigte auch ,wegen Lockerheit und elastischer Beschaffenheit der Arterien"* ungenaue Resultate. Nachdem auch ein Versuch mit getrockneten Gefäßen, von denen er Sehnitte in Wasser aufweichte und in Glyzerin einschloß, zu keinem befriedigenden Ziele führte, griff Schiele-Wiegandt zur Alkoholhärtung der GefäBstücke, die vorher zur Verhinderung der Schrumpfung 8 Tage lang in 2 prozentiger Lösung von bichromsaurem Kali gelegen hatten.

U̇ber die Schrumpfungsvorgänge bei dem letzteren Verfahren suchte ich mich durch einen Versuch zu orientieren. Er ergab:

Frisch

Aorta I

Aorta II

Länge $1,8 \mathrm{~cm}$

Breite $1,55 \mathrm{~cm}$

Dickè $\quad 1,74-1,88 \mathrm{~mm}$
2 Tage in $70 \%$ Alkohol

$6,0 \mathrm{~cm}$

$$
\text { Wanddicke } 1,44-1,48 \mathrm{~mm} \quad 1,00-1,04 \mathrm{~mm}
$$

\section{Frisch 8 Tage in $2 \%$} bichromsaurem Kali

$1,8 \mathrm{~cm}$

$1,6 \mathrm{~cm}$

$1,84-1,88 \mathrm{~mm}$ hierauf 5 Tage

in Alkohol

- $1,8 \mathrm{~cm}$

$1,6 \mathrm{~cm}$

$1,60-1,70 \mathrm{~mm}$ 
Durch Vorbehandlung mit bichromsaurem Kali wird also zunächst eine Quellung bewirkt und trotzdem die Dickenschrumpfung bei der nachfolgenden Alkoholhärtung nicht hintangehalten. Erfüllt aber die Methode den Zweck einer genauen Messung der wirklichen Wandstärke nicht, so hat sie überhaupt keinen Wert, weil die Schrumpfung in verschiedenen Gefäßen ungleich stark sich bei ein und derselben Methode einstellen kann, und der Fehler, der deshalb der Methode anhaftet, auch nicht als Konstante anzusehen wäre.

Wir haben, als wir diese Untersuchungen begannen, von diesen früheren, aber, wie eben gezeigt wurde, unbrauchbaren Dickenmessungen von $\mathrm{Sch}$ i eleW i e g a $n$ d t keine Kenntnis gehabt. Nun ist aber der Mangel zuverlässiger Be stimmungen der Wandstärke eine auffallenderweise immer noch nicht ausgefüllte Lücke in der Bearbeitung der Frage nach der Hypoplasie der Gefäße. Ja, es kann, wie wir glauben, dies interessante Problem zunächst auf gar keine andere Weise weitergefördert werden, als indem außer dem Durchmesser der Gefäßlichtung (Gefäßweite) auch endlich der Durchmesser der Gefäßwand selbst berücksichtigt wird. Man muß sich nur im vorhinein klar sein, daß die letztere allein auch keinen großen Wert hat, da bei Arterien vom muskulären Typus durch die Kontraktion eine Dickenzunahme der Wand resultiert. Dabei nimmt allerdings dann der Radius des Gefäßlumens ab; hieraus ergibt sich, daß nur die Berücksichtigung des Kalibers von Lichtung und Wandstärke zugleich in einem bestimmten Fall einen Schluß, über ein abweichendes Verhalten des untersuchten Gefäßrohres zuläßt.

Auf Veranlassung von Herrn Professor R össle unternahm ich es deshalb, in systematischen Messungen Umfang und Wanddicke von gesunden und kranken

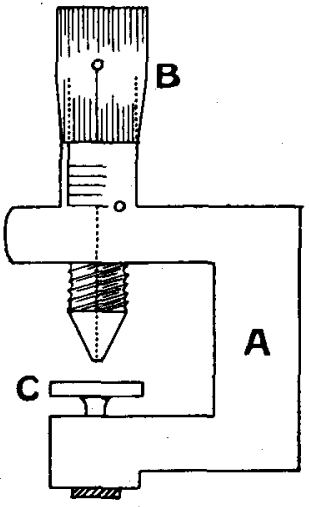
Arterien zu bestimmen.

Ich benutzte zur Dickenmessung ein von $\mathrm{R}$ össle modifiziertes Drahtmikrometer. Das Instrument besteht aus einem eisernen Bügel A. Die Schraube B bewegt sich gegen ein horizontal gestelltes Plättchen C, welches, in Augenhöhe gebracht, das zu messende GefäBstück trägt. Durch eine ganze Umdrehung des Schraubenkopfes entfernt sich die etwas abgestumpfte Schraubenspitze von dem horizontalen Plättchen um $1 \mathrm{~mm}$. Da die Peripherie des Schraubenkopfes in 50 gleiche Teile geteilt ist, kann man noch Dickendifferenzen von $0,02 \mathrm{~mm}$ messen.

Was das Material anbetrifft, so verwandte ich frische Gefäßstücke. Nach möglichst sorgfältiger Entfernung des adventitiellen Gewebes mittels Schere wurde die Adventitiaseite des Gefäßes mit Fließpapier getrocknet und dann die präparierte Fläche auf das Mikrometertischchen vollkommen plan aufgelegt. Dazu ist kein Druck notwendig. Sodann wurde die abgestumpfte Spitze von oben her der Intima genähert und die Messung in dem Moment vorgenommen, wo die Spitze mit ihrer kleinen Fläche die Intima berührt. Schon bei geringer Utbung kann man jede Druckäußerung auf die Intima und also eine fehlerhafte künstliche Verdünnung der Gefäßwand vermeiden, insbesondere wenn man immer bei gleicher Beleuchtung arbeitet, wobei man den Moment der Berührung richtig abschätzen lernt. $\mathrm{Zu}$ bemerken ist, daß gehärtete Stückchen. nicht mehr festkleben, so daB die Fehlergrenze viel höher liegt. Immerhin scheint $\mathrm{z}$. B. bei der Formalinhärtung die Schrumpfung geringer zu sein als bei der oben beschriebenen Methode von $\mathrm{Schiele-Wiegandt;} \mathrm{vergleichende} \mathrm{Dickenmessungen} \mathrm{von} \mathrm{frischen} \mathrm{und} \mathrm{von} \mathrm{formol-}$ gehärteten Gefäßen ergaben z. B.: 


\begin{tabular}{|c|c|c|c|c|}
\hline . & Frisch & & $\begin{array}{l}2-3 \text { Tage in } \\
\text { Formalinlös }\end{array}$ & $\begin{array}{l}10 \% \\
\text { ung }\end{array}$ \\
\hline Pulmonalis & $1,32-1,46$ & $\mathrm{~mm}$ & $1,40 \mathrm{~mm}$ & \\
\hline Aorta über Klappe & $1,72-1,96$ & 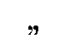 & 1,97, & \\
\hline Aorta an Teilungsstelle & $1,16-1,20$ & " & $1,24-1,26$ & $\mathrm{~mm}$ \\
\hline Carotis & $1,00-1,04$ & & 0,98 & " \\
\hline Brustaorta & $1,50-1,62$ & " & $1,68-1,80$ & $\eta$ \\
\hline " & $1,34-1,36$ & ” & $1,34-1,38$ & " \\
\hline
\end{tabular}

Diese Tatsache war mir in Hinsicht auf die spätere mikroskopische Messung der einzelnen Wandschichten in Schnitten und für den Vergleich der Resultate dieser letzteren Messungen mit den durch das Dickenmikrometer an frischen Gefäßen erhaltenen Zahlen wertvoll. Dies letztere gibt ja nur die Gesamtstärke der Gefäßrohrschichten an; es war aber notwendig, von der Norm abweichende Befunde auf Veränderungen bestimmter Schichten, z. B. der Intima oder der Media, zurückzuführen, und dazu taugte nur die Messung mittels des Okularmikrometers an Schnitten. Der Vergleich zwischen beiden Methoden ergab mir recht befriedigende Utbereinstimmung insofern, als das Ergebnis der makroskopischen Dickenmessung sich fast mit der Messung von Intima + Media an Formolgefrierschnitten mittels des Okularmikrometers deckte.

Ferner wurde die Größe eines Fehlers, der unserer Methode infolge der planen Ausbreitung der Gefäßwand auf die Unterlage anhaftet, gemessen. Da ich fast immer Stückchen von längs aufgeschnittenen Gafäßen maß, mußte ich nämlich prüfen, ob nicht die dabei veränderten Spannungsverhältnisse schon Dickenabnahme oder -zunahme bewirkten. Durch die Entfaltung des Gefäßrohrstückes zu einem planparallelen Ausschnitt mußte ja die Dicke der Gefäßwand schon abnehmen, und zwar um so mehr in den einzelnen Schichten, je mehr eine betreffende Gewebslage dem Lumen zulag, d. h. je stärkere Krümmung sie in normaler Situation gehabt hatte. Vergleichende Untersuchungen zeigten nun, daß praktisch der Fehler an den großen Arterien sehr gering war, indem gegenüber dem unaufgeschnittenen Gefäße nur eine Differenz von $0,02 \mathrm{~mm}$ sich ergab, eine Zahl, die noch im Bereich der geringen Messungsfehler liegt, die unserer Methode anhaften, und demnach für die gleichmäßig erhobenen Ergebnisse nicht in Betracht kommt.

$\begin{array}{lcc} & \begin{array}{c}\text { Beispiele: } \\ \text { Unaufgeschnitten }\end{array} & \begin{array}{c}\text { Aufgeschnitten } \\ \text { Aorta hinter Bogen }\end{array} \\ \text { Aorta am Zwerchfell } & 1,36 \mathrm{~cm} & 1,36-1,38 \mathrm{~cm} \\ \text { Art. renalis dextra } & 1,26 \% & 1,24 \quad \\ \text { Art. renalis sin. } & 0,56 " & 0,58,\end{array}$

Neben diesen Wanddicken- und Umfangmessungen, die ich in etwa 220 Fällen vorgenommen habe, führte ich auch einige Gewichtsmessungen aus. Dies geschah, um einem naheliegenden Einwande gegen unsere Methode zu begegnen. Er besteht: darin, daß man sagen könnte, daß selbst die Messung der Dicke an zahlreichen Punkten eines Gefäßes, besonders wenn dieses krankhaft verändert ist, kein genü- 
gendes Bild für die Maße an funktionierendem oder überhaupt vorhandenem Gefäßgewebe gäbe. Wir nahmen deshalb das Gewicht von $25 \mathrm{qcm}$ der Aorta über der Klappe oder rechneten, falls sich nicht so viel ausschneiden ließ, von der erhaltenen Zahl eines etwas kleineren Stückes auf $25 \mathrm{qcm}$ um. Diese Kontrolle unserer Dickenmessungen durch Gewichtsbestimmung eines konstant großen Aortastückes bestärkte uns in der Utberzeugung, daß unsere Mikrometermethode etwas taugte, denn wir erhielten dieselben Resultate; z. B. hat sich gezeigt, daß auch das Aortengewicht im selben Verhältnis wie die Dicke mit dem Alter zunimmt.

\section{Beispiel:}

Gewicht von

Weib $17 \mathrm{~J} . \quad$ Mann $22 \mathrm{~J}$.

$25 \mathrm{qcm}$ Aorta über der Klappe $4,25 \mathrm{~g}$

$4,33 \mathrm{~g}$

Mann $34 \mathrm{~J}$. $4,48 \mathrm{~g}$

Mann $58 \mathrm{~J}$. $5,28 \mathrm{~g}$

Um als Grundlage für die Beurteilung Normalzahlen nach Alter und Geschlecht zu erlangen, habe ich zunächst an einer Reihe von gesunden, gehörig entwickelten, plötzlich durch Unfall, Gehirnkrankheiten oder durch Sepsis nach Operation verstorbenen Individuen Messungen ausgeführt und diese Fälle in Tabelle I zusammengestellt. Es zeigte sich, daß eine kräftige Konstitution in der Tat Hand in Hand geht mit stark entwickeltem Gefäßsystem sowohl bezüglich der Gefäßwanddicke als namentlich des Umfanges (vgl. z. B. S. Nr. 91/09, 30 jähriger Mann, S. Nr. 1095/08, 34 jähriger Mann, S. Nr. 964/08, 54 jähriger Mann).

Tabelle II enthält das arithmetische Mittel meiner sämtlichen Messungen (ausgenommen die Fälle von luetiseher Aortitis), geordnet nach Geschlecht und Alter. Von jedem Gefäßstück wurde die dickste und die dünnste Stelle notiert; nur lineale Prominenzen und zirkumskripte Auftreibungen ließ ich außer Betracht; man kann auf diese Weise die Gefäßwanddicke vielleicht besser kennen lernen als durch einen einzigen Mittelwert. Uber physiologische Dickendifferenzen an verschiedenen Stellen der Zirkumferenz in gleicher Aortahöhe werde ich weiter unten berichten.

Die Fälle mit luetischer Aortitis sind deshalb weggelassen, weil die Aufzeichnung der äußerst unregelmäßigen Wandverhältnisse mit den feinen, trichterförmigen Verdünnungen und den gummösen Verdickungen wenig Wert für die Gesamtbetrachtung in unserer Frage hätte. Dazu kommt, daß durch entzündliche Vorgänge in Media und Adventitia diese beiden Schichten in ähnlicher Weise miteinander verbunden werden wie etwa die Niere und die Nierenkapsel bei chronischer interstitieller Nephritis, so daß von einer zuverlässigen und gleichmäßigen Entfernung der Adventitia durch einfache Präparation, wie sie sonst leicht gelang, in diesen Fällen nicht die Rede sein kann.

Zum Verständnis der Tabelle sei darauf aufmerksam gemacht, daß die in Klammer gesetzte Zahl die Anzahl der Fälle angibt, aus denen der Mittelwert ausgezogen und darüber vermerkt ist. Bezüglich des letzten Falles in der Tabelle (Weib über 81 Jahre) muß bemerkt werden, daß er wegen der abnorm hohen 
Tabelle I.

Normal

\begin{tabular}{|c|c|c|c|c|c|c|c|}
\hline $\begin{array}{l}\text { Sektions- } \\
\text { nummer }\end{array}$ & $\begin{array}{l}\text { Alter } \\
\text { und Ge- } \\
\text { schlecht }\end{array}$ & $\mathrm{Hav}$ & $\begin{array}{l}\text { Art. Pulm. } \\
\text { v. } \quad \text { D. }\end{array}$ & $\begin{array}{l}\text { Aorta } \\
\text { über } \\
\text { Klappen } \\
\text { U. D. D. }\end{array}$ & $\begin{array}{l}\text { Aorta } \\
\text { hinter } \\
\text { Bogen } \\
\text { v. D. }\end{array}$ & $\begin{array}{l}\text { Aorta am } \\
\text { Zwerchfell } \\
\text { v. D. }\end{array}$ & $\begin{array}{l}\text { Teilungs } \\
\text { stelle } \\
\text { U. D. }\end{array}$ \\
\hline & & Abruch & $5,2\left\{\begin{array}{l}0,78 \\
0,96\end{array}\right.$ & $4,3\left\{\begin{array}{l}1,40 \\
1,70\end{array}\right.$ & $3,3\left\{\begin{array}{l}0,60 \\
1,00 \\
1,22\end{array}\right.$ & $3,1\left\{\begin{array}{l}1,80 \\
1,06\end{array}\right.$ & $2,3\left\{\begin{array}{l}0 \\
0\end{array}\right.$ \\
\hline $101 / 09$ & & Eitrige Meningitis & $5,0\left\{\begin{array}{l}0,94 \\
1,04\end{array}\right\}$ & $4,3\left\{\begin{array}{l}1,20 \\
1,40\end{array}\right.$ & $3,1\left\{\begin{array}{l}1,2 \\
0,90 \\
0,94\end{array}\right\}$ & $2,9\left\{\begin{array}{l}0,82 \\
0,92\end{array}\right.$ & $2,1\left\{\begin{array}{l}0 \\
0\end{array}\right.$ \\
\hline $528 / 09$ & & Tod durch Erschießen & $6,0\left\{\begin{array}{l}0,90 \\
1,04 \\
1,24\end{array}\right.$ & $5,5\left\{\begin{array}{l}1,42 \\
1,56\end{array}\right.$ & $4,1\left\{\begin{array}{l}1,04 \\
1,24\end{array}\right\}$ & $3,8\left\{\begin{array}{l}1,04 \\
1,18\end{array}\right.$ & $2,7\left\{\begin{array}{l}0 \\
1\end{array}\right.$ \\
\hline $76 / 09$ & & $\begin{array}{l}\text { Sepsis nach Opes } \\
\text { in Bauchhöhle }\end{array}$ & $5,7\left\{\begin{array}{l}0,78 \\
1,26\end{array}\right.$ & $5,1\left\{\begin{array}{l}1,30 \\
1,60 \\
1,80\end{array}\right.$ & $4,1\left\{\begin{array}{l}0,96 \\
1,10 \\
1,50\end{array} \mid\right.$ & $3,5\left\{\begin{array}{l}1,04 \\
1,18\end{array}\right.$ & 2,7 \\
\hline $1123 / 08$ & & Hirntumor & $6,0\left\{\begin{array}{l}1,04 \\
1,40\end{array}\right.$ & $5,5\left\{\begin{array}{l}1,56 \\
1,78\end{array}\right.$ & $4,3\left\{\begin{array}{l}1,10 \\
1,50\end{array}\right.$ & $4,0\left\{\begin{array}{l}1,26 \\
1,40\end{array}\right.$ & 3,0 \\
\hline $273 / 09$ & & Zyankalivergiftung & $6,0\left\{\begin{array}{l}0,98 \\
1,18\end{array}\right.$ & $5,0\left\{\begin{array}{l}1,66 \\
1,96\end{array}\right.$ & $4,4\left\{\begin{array}{l}1,26 \\
1,44\end{array}\right\}$ & $4,1\left\{\begin{array}{l}1,16 \\
1,30\end{array}\right.$ & 2,9 \\
\hline $279 / 09$ & & $\begin{array}{l}\text { Bruc } \\
\text { Myel }\end{array}$ & $6,2\left\{\begin{array}{l}1,04 \\
1,40\end{array}\right.$ & $5,9\left\{\begin{array}{l}1,60 \\
1,76\end{array}\right.$ & $4,8\left\{\begin{array}{l}1,00 \\
1,36\end{array}\right.$ & $4,3\left\{\begin{array}{l}0,96 \\
1,20\end{array}\right.$ & $3,2\left\{\begin{array}{l}0 \\
1\end{array}\right.$ \\
\hline $34 / 09$ & & durch & $6,1\left\{\begin{array}{l}0,96 \\
1,30\end{array}\right.$ & $5,6\left\{\begin{array}{l}1,46 \\
1,94\end{array}\right.$ & $4,2\left\{\begin{array}{l}1,14 \\
1,32\end{array}\right\}$ & $4,0\left\{\begin{array}{l}1,18 \\
1,30\end{array}\right.$ & 3,1 \\
\hline $233 / 09$ & & $\begin{array}{l}\text { Sepsis ause } \\
\text { diffuser ei }\end{array}$ & $5,5\left\{\begin{array}{l}0,92 \\
1,02\end{array}\right.$ & $5,5\left\{\begin{array}{l}1,66 \\
1,90\end{array}\right.$ & $4,3\left\{\begin{array}{l}1,14 \\
1,30\end{array}\right.$ & $3,9\left\{\begin{array}{l}1,18 \\
1,30\end{array}\right.$ & 3,1 \\
\hline $1007 / 08$ & & Eitrige Leptomeningitis & $6,0\left\{\begin{array}{l}0,98 \\
1,38\end{array}\right.$ & $6,0\left\{\begin{array}{l}1,66 \\
1,72\end{array}\right.$ & $4,0\left\{\begin{array}{l}1,26 \\
1,34\end{array}\right.$ & $4,0 \quad 1,24$ & $3,0\left\{\begin{array}{l}0 \\
1\end{array}\right.$ \\
\hline $216 / 09$ & & $\begin{array}{c}\text { Diffus eitrige Lepto- } \\
\text { meningitis }\end{array}$ & $7,0\left\{\begin{array}{l}0,80 \\
1,10\end{array}\right.$ & $6,0\left\{\begin{array}{l}1,40 \\
1,70\end{array}\right.$ & $4,5\left\{\begin{array}{l}1,20 \\
1,40 \\
1,60\end{array}\right)$ & $4,0\left\{\begin{array}{l}1,06 \\
1,32\end{array}\right.$ & $3,2\left\{\begin{array}{l}1 \\
1\end{array}\right.$ \\
\hline $91 / 09$ & & Schäc & $8,0\left\{\begin{array}{l}1,12 \\
1,18\end{array}\right.$ & $7,5\left\{\begin{array}{l}1,80 \\
2,08\end{array}\right.$ & $5,7\left\{\begin{array}{l}1,54 \\
1,70\end{array}\right.$ & $5,0\left\{\begin{array}{l}1,54 \\
1,78\end{array}\right.$ & 4,0 \\
\hline $172 / 09$ & & $\begin{array}{l}\text { Generalisierte Miliar- } \\
\text { tuberkulose }\end{array}$ & $7,0\left\{\begin{array}{l}0,90 \\
1,30 \\
1,50\end{array}\right\}$ & $6,0\left\{\begin{array}{l}1,54 \\
1,94\end{array}\right.$ & $\left\{\begin{array}{l}1,56 \\
1,70\end{array}\right.$ & $4,6\left\{\begin{array}{l}1,48 \\
1,76\end{array}\right.$ & $3,7\{$ \\
\hline $1095 / 08$ & & Sturz aus & $8,5\left\{\begin{array}{l}1,04 \\
1,16\end{array}\right.$ & $6,5 \quad 1,60$ & $5,3\left\{\begin{array}{l}1,40 \\
1,50\end{array}\right.$ & $4,8\left\{\begin{array}{l}1,30 \\
1,40\end{array}\right.$ & 3,6 \\
\hline $214 / 09$ & & $\begin{array}{l}\text { des rechten } \\
\text { ns ohne Ar- } \\
\text { erose }\end{array}$ & $6,5\left\{\begin{array}{l}0,96 \\
1,16\end{array}\right.$ & $6,3\left\{\begin{array}{l}1,66 \\
2,00\end{array}\right.$ & $4,8\left\{\begin{array}{l}1,56 \\
1,76\end{array}\right.$ & $4,4\left\{\begin{array}{l}1,44 \\
1,70\end{array}\right.$ & 3,5 \\
\hline $37 / 09$ & & $\begin{array}{l}\text { Apoplexie des linken } \\
\text { Sehhügels }\end{array}$ & $6,0\left\{\begin{array}{l}0,88 \\
0,98\end{array}\right.$ & $6,5\left\{\begin{array}{l}1,80 \\
1,94\end{array}\right\}$ & $5,3\left\{\begin{array}{l}1,60 \\
1,64\end{array}\right.$ & $4,8\left\{\begin{array}{l}1,58 \\
1,66\end{array}\right.$ & $3,7\left\{\begin{array}{l}1 \\
1\end{array}\right.$ \\
\hline $106 / 09$ & & Schädelbruch & $7,0\left\{\begin{array}{l}1,00 \\
1,18\end{array}\right.$ & $6,5\left\{\begin{array}{l}1,70 \\
1,90\end{array}\right.$ & $4,8\left\{\begin{array}{l}1,24 \\
1,52\end{array}\right.$ & $4,3\left\{\begin{array}{l}1,18 \\
1,44\end{array}\right.$ & $3,6\left\{\begin{array}{l}1 \\
1\end{array}\right.$ \\
\hline 9 & & Tod durch Ve & & $8,1\left\{\begin{array}{l}2,00 \\
2,10\end{array}\right.$ & $6,0\left\{\begin{array}{l}1,65 \\
1,72\end{array}\right.$ & $5,5\left\{\begin{array}{l}1,46 \\
1,50\end{array}\right.$ & 4,21 \\
\hline 1 & & letzung des & $7,1\left\{\begin{array}{l}0,94 \\
1,12\end{array}\right.$ & $7,4\left\{\begin{array}{l}1,84 \\
1,94\end{array}\right.$ & $6,1\left\{\begin{array}{l}1,68 \\
1,80\end{array}\right.$ & $5,6\left\{\begin{array}{l}1,60 \\
1,70\end{array}\right.$ & $4,4\{$ \\
\hline
\end{tabular}

Zahlen als durchaus pathologiseh zu betrachten ist. Die Untersuchung meiner Zahlen ergibt folgendes:

1. A o r t a. Der Umfang der Aorta nimmt an allen gemessenen Stellen vom ersten Lebensjahre bis zum Greisenalter ständig zu und ist beim Mann immer 
U. = Umfang in Zentimetern

D. $=$ Dicke in Millimetern.

Gefäße.

\begin{tabular}{|c|c|c|c|c|c|c|c|c|}
\hline $\begin{array}{l}\text { Art. iliaca } \\
\text { communis } \\
\text { U. D. }\end{array}$ & $\begin{array}{l}\text { Carotis } \\
\text { communis } \\
\text { D. U. }\end{array}$ & & $\begin{array}{l}\text { art. } \\
\text { lalis } \\
\text { xtr. } \\
\text { D. }\end{array}$ & $\begin{array}{l}\text { Art. } \\
\text { renalis } \\
\text { sin. } \\
\text { v. D. }\end{array}$ & $\begin{array}{c}\text { Herz- } \\
\text { gewicht } \\
g\end{array}$ & $\begin{array}{c}\text { Körper- } \\
\text { gewicht } \\
\text { kg }\end{array}$ & $\begin{array}{c}\text { Körper- } \\
\text { länge } \\
\text { em }\end{array}$ & \\
\hline $1,5\left\{\begin{array}{l}0,68 \\
0,72\end{array}\right.$ & $1,4\left\{\begin{array}{l}0,60 \\
0,80\end{array}\right.$ & 1,0 & 0,50 & $1,0\left\{\begin{array}{l}0,38 \\
0,48\end{array}\right.$ & 140 & 21 & 123 & \\
\hline $1,4 \quad 0,84$ & $1,4\left\{\begin{array}{l}0,72 \\
0,82\end{array}\right.$ & & & & 148 & 23 & 163 & . \\
\hline $1,8\left\{\begin{array}{l}0,70 \\
0,80\end{array}\right.$ & & 1,3 & 0,50 & $1,3\left\{\begin{array}{l}0,56 \\
0,66\end{array}\right.$ & 260 & 49 & 161 & \\
\hline $\mathbf{1 , 6}\left\{\begin{array}{l}0,80 \\
1,00\end{array}\right.$ & & $1,2\{$ & $\left\{\begin{array}{l}1,56 \\
0,62\end{array}\right.$ & $1,2\left\{\begin{array}{l}0,52 \\
0,60\end{array}\right.$ & 275 & 53 & 156 & $\begin{array}{l}25 \mathrm{gcm} \text { der Aorta über } \\
\text { Klappen } 4,25 \mathrm{~g} \text {. }\end{array}$ \\
\hline $2,1 \quad 0,88$ & & $1,3\{$ & $\begin{array}{l}0,54 \\
0,58\end{array}$ & $1,3\left\{\begin{array}{l}0,50 \\
0,66\end{array}\right.$ & 325 & 48 & 172 & \\
\hline $2,0\left\{\begin{array}{l}0,70 \\
0,78\end{array}\right.$ & $1,6\left\{\begin{array}{l}1,00 \\
1,14\end{array}\right.$ & $1,4\{$ & & & 470 & 78 & 168 & \\
\hline $2,1\left\{\begin{array}{l}0,76 \\
1,06\end{array}\right.$ & & & $\begin{array}{l}0,56 \\
0,66\end{array}$ & 1,2 throm & 410 & 62 & 164 & \\
\hline $2,3\left\{\begin{array}{l}0,98 \\
1,10\end{array}\right.$ & $1,9\left\{\begin{array}{l}0,80 \\
0,90\end{array}\right.$ & 1,5 & 0,48 & $1,4\left\{\begin{array}{l}0,52 \\
0,68\end{array}\right.$ & 350 & 56 & 168 & 25 qcm Aorta $4,33 \mathrm{~g}$. \\
\hline $2,0\left\{\begin{array}{l}0,76 \\
1,04\end{array}\right.$ & & & & & 335 & 47 & 161 & \\
\hline & $1,5\left\{\begin{array}{l}0,85 \\
0,94\end{array}\right.$ & & & & 270 & 47 & 150 & \\
\hline $2,0\left\{\begin{array}{c}0,84 \\
0,90\end{array}\right.$ & & $1,7\{$ & $\begin{array}{l}0,40 \\
0,70\end{array}$ & & 330 & 48 & 167 & \\
\hline $2,7\left\{\begin{array}{l}1,00 \\
1,36\end{array}\right.$ & $2,2\left\{\begin{array}{l}1,00 \\
1,06\end{array}\right.$ & & & & 370 & 64 & 195 & \\
\hline $2,5\left\{\begin{array}{l}0,80 \\
0,90\end{array}\right.$ & $1,9\left\{\begin{array}{l}0,82 \\
1,02\end{array}\right.$ & $1,8\{$ & $\left\{\begin{array}{l}0,54 \\
0,70\end{array}\right.$ & $1,7 \quad 0,56$ & 300 & 56 & 168 & \\
\hline $2,8\left\{\begin{array}{l}0,80 \\
0,86\end{array}\right.$ & $2,1\left\{\begin{array}{l}0,72 \\
0,80\end{array}\right\}$ & 1,4 & 0,54 & $1,6 \quad 0,48$ & 380 & 81 & 172 & 25 qcm Aorta $4,48 \mathrm{~g}$. \\
\hline $2,5\left\{\begin{array}{l}0,90 \\
1,10 \\
1,40\end{array}\right.$ & & $1,5\{$ & $\left\{\begin{array}{l}0,70 \\
0,80\end{array}\right.$ & & 325 & 49 & 153 & \\
\hline $2,6\left\{\begin{array}{l}1,02 \\
1,32\end{array}\right.$ & & & $\left\{\begin{array}{l}0,80 \\
0,94\end{array}\right.$ & $1,6\left\{\begin{array}{l}0,92 \\
0,94\end{array}\right.$ & 300 & 52 & 158 & \\
\hline $2,2\left\{\begin{array}{l}0,76 \\
0,80\end{array}\right.$ & & & & & 280 & 50 & 147 & \\
\hline $2,7\left\{\begin{array}{l}1,08 \\
1,10\end{array}\right.$ & $2,6\left\{\begin{array}{l}1,02 \\
1,10\end{array}\right.$ & 1,8 & 0,60 & $1,7\left\{\begin{array}{l}0,70 \\
0,74\end{array}\right.$ & 340 & 72 & 175 & \\
\hline $2,9\left\{\begin{array}{l}0,82 \\
1,12\end{array}\right.$ & $2,2\left\{\begin{array}{l}1,26 \\
1,38\end{array}\right.$ & 2,0 & {$\left[\begin{array}{l}0,64 \\
0,68\end{array}\right.$} & $1,8\left\{\begin{array}{l}0,66 \\
0,76\end{array}\right.$ & 315 & 58 & 166 & $25 \mathrm{qcm}$ Aorta $5,28 \mathrm{~g}$. \\
\hline
\end{tabular}

größer als beim Weibe. Nur etwa bis zum 50. Jahre scheint wirkliches Wachstum vorzuliegen, später öfters Dilatation, da sich dann die bis jetzt proportional gewachsene Wanddicke unregelmäßig verhält und ab und zu vermindert. Der in der Jugend deutliche Dickenunterschied bei den Geschlechtern nimmt mit den 
Tabelle II.

Mittelwerte aus

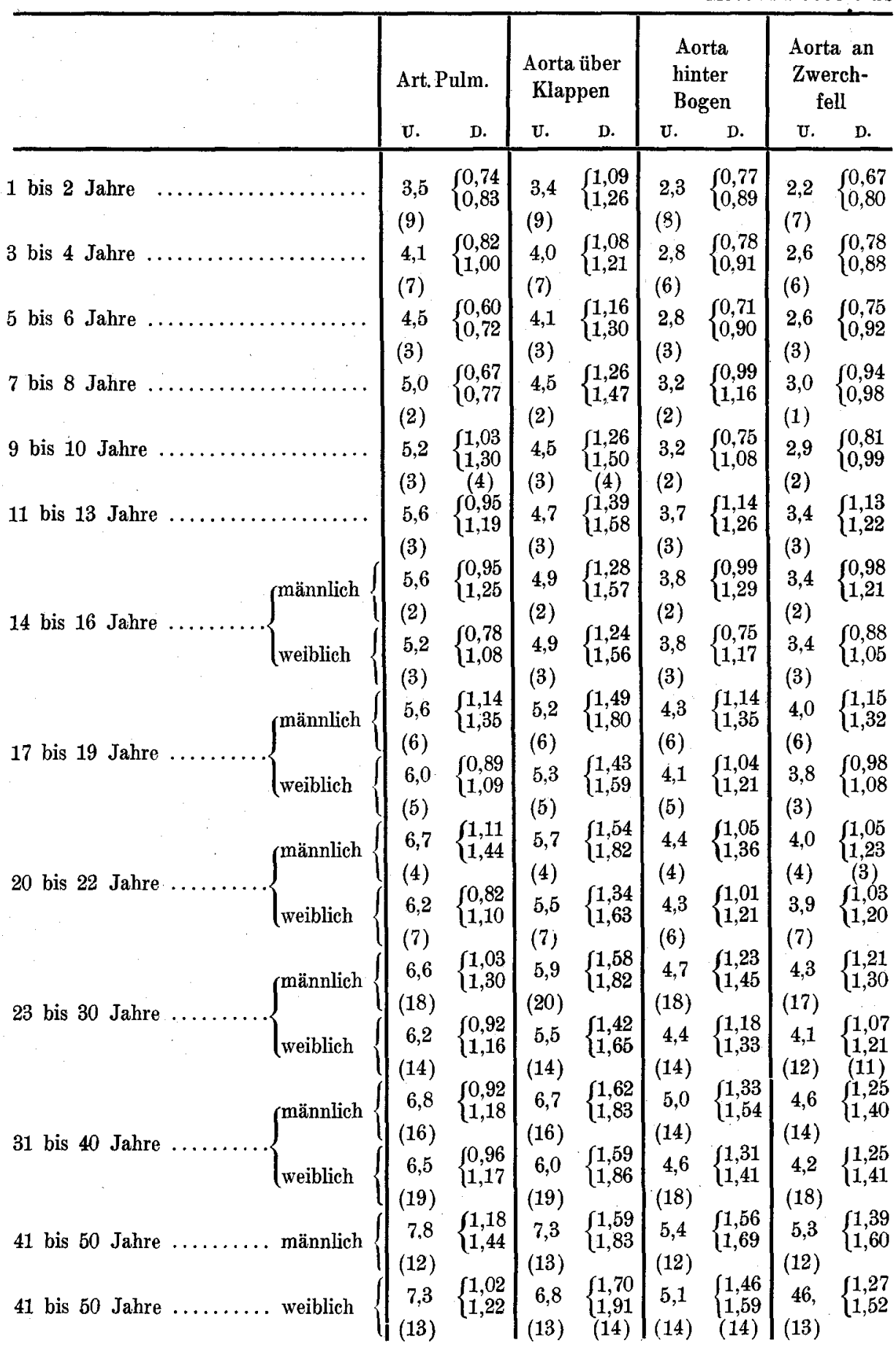


sämtlichen Messungen.

$U .=$ Umfang in Zentimetern

\begin{tabular}{|c|c|c|c|c|c|c|c|c|c|c|c|c|}
\hline \multicolumn{2}{|c|}{$\begin{array}{c}\text { Aorta an } \\
\text { Teilungs- } \\
\text { stelle } \\
\text { U. D. }\end{array}$} & \multicolumn{2}{|c|}{$\begin{array}{l}\text { Art. } \\
\text { iliaca } \\
\text { com. }\end{array}$} & \multicolumn{2}{|c|}{$\begin{array}{c}\text { Carotis } \\
\text { com. }\end{array}$} & \multicolumn{2}{|c|}{$\begin{array}{c}\text { Art. } \\
\text { renalis } \\
\text { dex. }\end{array}$} & \multicolumn{2}{|c|}{$\begin{array}{l}\text { Art. } \\
\text { renalis } \\
\text { sin. }\end{array}$} & $\begin{array}{c}\text { Herz- } \\
\text { gewicht } \\
\mathrm{g}\end{array}$ & $\begin{array}{c}\text { Körper- } \\
\text { länge } \\
\mathrm{om}\end{array}$ & $\begin{array}{l}\text { Körper- } \\
\text { gewicht } \\
\text { kg }\end{array}$ \\
\hline & $\{0,67$ & & 00,51 & & 0,56 & & & & & & & \\
\hline 1,0 & $\{0,77$ & 1,0 & $\{0,59$ & 1,2 & $\{0,65$ & & & & & 66,0 & 79,0 & 8,7 \\
\hline (7) & & (7) & & (5) & & & & & & (9) & (8) & (8) \\
\hline 1,6 & $\left\{\begin{array}{l}0,69 \\
0,81\end{array}\right.$ & 1,1 & $\left\{\begin{array}{l}0,49 \\
0,69\end{array}\right.$ & 1,3 & $\left\{\begin{array}{l}0,66 \\
0,70\end{array}\right.$ & & & & & 76,0 & 95,0 & 12,5 \\
\hline (6) & & (5) & & (5) & & & & & & (7) & (7) & (7) \\
\hline 1,7 & $\left\{\begin{array}{l}0,72 \\
0,80\end{array}\right.$ & 1,2 & $\left\{\begin{array}{l}0,56 \\
0,63\end{array}\right.$ & 1,4 & $\left\{\begin{array}{l}0,58 \\
0,76\end{array}\right.$ & & 0,40 & $0,7\{$ & $\left\{\begin{array}{l}0,36 \\
0,40\end{array}\right.$ & & & \\
\hline (3) & & (3) & & (3) & & $(1)$ & & (1) & & & & \\
\hline & $\left\{\begin{array}{l}0,92 \\
0,96\end{array}\right.$ & 1,4 & $\left\{\begin{array}{l}0,88 \\
0,90\end{array}\right.$ & 1,5 & $\left\{\begin{array}{l}0,77 \\
0,88\end{array}\right.$ & & & $0,9\{$ & $\left\{\begin{array}{l}0,36 \\
0,38\end{array}\right.$ & 149,0 & & \\
\hline (1) & & (I) & & (2) & & & & (1) & & (2) & & \\
\hline 2,2 & $\left\{\begin{array}{l}0,80 \\
0,96\end{array}\right.$ & 1,4 & $\left\{\begin{array}{l}0,76 \\
0,82\end{array}\right.$ & 1,4 & $\left\{\begin{array}{l}0,66 \\
0,81\end{array}\right.$ & 1,0 & 0,50 & $1,0\{$ & $\left\{\begin{array}{l}0,38 \\
0,48\end{array}\right.$ & 151,0 & 122,0 & 21,6 \\
\hline (2) & & (2) & & (2) & & $(1)$ & & (1) & & (3) & (3) & (3) \\
\hline 2,6 & $\left\{\begin{array}{l}1,06 \\
1,19\end{array}\right.$ & 1,7 & $\left\{\begin{array}{l}0,88 \\
0,92\end{array}\right.$ & 1,6 & $\left\{\begin{array}{l}0,83 \\
0,89\end{array}\right.$ & 1,1 & $\left\{\begin{array}{l}0,64 \\
0,65\end{array}\right.$ & 1,1 & 0,46 & 280,0 & 147,0 & 34,6 \\
\hline (3) & & (3) & & (3) & & $(3)$ & & (1) & & (3) & (2) & (3) \\
\hline 2,6 & $\left\{\begin{array}{l}0,99 \\
1,26\end{array}\right.$ & 1,9 & $\left\{\begin{array}{l}0,96 \\
1,20\end{array}\right.$ & 1,7 & $\left\{\begin{array}{l}0,66 \\
0,98\end{array}\right.$ & 1,0 & $\left\{\begin{array}{l}0,44 \\
0,64\end{array}\right.$ & & $\left\{\begin{array}{l}0,40 \\
0,56\end{array}\right.$ & 210,0 & 161,0 & 35,5 \\
\hline (2) & & (1) & & (2) & & (1) & & & & (2) & (2) & (2) \\
\hline 2,5 & $\left\{\begin{array}{l}0,92 \\
1,12\end{array}\right.$ & 1,7 & $\left\{\begin{array}{l}0,64 \\
0,86\end{array}\right.$ & 1,7 & $\left\{\begin{array}{l}0,72 \\
0,84\end{array}\right.$ & 1,2 & $\left\{\begin{array}{l}0,45 \\
0,50\end{array}\right.$ & $1,2\{$ & $\left\{\begin{array}{l}0,64 \\
0,72\end{array}\right.$ & 223,0 & 143,6 & 33,1 \\
\hline (3) & & (3) & & (3) & & (2) & & (1) & & (3) & (3) & (3) \\
\hline 2,9 & $\left\{\begin{array}{l}1,09 \\
1,24\end{array}\right.$ & 2,0 & $\left\{\begin{array}{l}0,85 \\
1,00\end{array}\right.$ & 1,7 & $\left\{\begin{array}{l}0,85 \\
0,99\end{array}\right.$ & 1,2 & $\left\{\begin{array}{l}0,54 \\
0,60\end{array}\right.$ & & $\left\{\begin{array}{l}0,47 \\
0,59\end{array}\right.$ & 402,5 & 163,3 & 53,4 \\
\hline (6) & & (6) & & (4) & & $(6)$ & & (2) & & (6) & (6) & (6) \\
\hline 2,8 & $\{1,01\}$ & 1,8 & $\left\{\begin{array}{l}0,82 \\
0,98\end{array}\right.$ & 1,8 & $\left\{\begin{array}{l}0,60 \\
07\end{array}\right.$ & 1,2 & $\left\{\begin{array}{l}0,54 \\
0,57\end{array}\right.$ & $1,2\{$ & $\left\{\begin{array}{l}0,46 \\
0,5\end{array}\right.$ & 234,0 & 157,6 & 42,8 \\
\hline (5) & & $(5)$ & & (4) & & $(2)$ & & (3) & & (5) & (5) & (5) \\
\hline 3,1 & $\left\{\begin{array}{l}1,04 \\
1,24\end{array}\right.$ & 2,2 & $\left\{\begin{array}{l}0,83 \\
1,03\end{array}\right.$ & 1,9 & $\left\{\begin{array}{l}0,87 \\
0,95\end{array}\right.$ & 1,3 & $\left\{\begin{array}{l}0,50 \\
0,57\end{array}\right.$ & $1,3\{$ & $\left\{\begin{array}{l}0,48 \\
0,62\end{array}\right.$ & 427,5 & 165,0 & 58,5 \\
\hline (3) & & (3) & & (2) & & $(3)$ & & (3) & (2) & (4) & (4) & (4) \\
\hline 2,9 & $\left\{\begin{array}{l}0,94 \\
1,22\end{array}\right.$ & 1,9 & $\left\{\begin{array}{l}0,80 \\
0,99\end{array}\right.$ & 1,7 & $\left\{\begin{array}{l}0,80 \\
083\end{array}\right.$ & 1,3 & $\left\{\begin{array}{l}0,49 \\
060\end{array}\right.$ & $1,2\{$ & $\left\{\begin{array}{l}0,46 \\
0,62\end{array}\right.$ & 250,0 & 161,1 & 44,7 \\
\hline (7) & & (7) & & (5) & & $(5)$ & & (5) & & (7) & (7) & (7) \\
\hline 3,3 & $\left\{\begin{array}{l}1,09 \\
1,26\end{array}\right.$ & 2,2 & $\left\{\begin{array}{l}0,87 \\
1,06\end{array}\right.$ & 1,9 & $\left\{\begin{array}{l}0,81 \\
0,94\end{array}\right.$ & 1,4 & $\left\{\begin{array}{l}0,49 \\
0,60\end{array}\right.$ & 1,3 & $\left\{\begin{array}{l}0,49 \\
0,60\end{array}\right.$ & 342,0 & 169,8 & 52,1 \\
\hline (15) & & $(15)$ & & (12) & & $(9)$ & & (8) & & (19) & (20) & $(20)$ \\
\hline 3,0 & $\left\{\begin{array}{l}1,00 \\
1,18\end{array}\right.$ & 2,0 & $\left\{\begin{array}{l}0,7 \\
0,0\end{array}\right.$ & 1,7 & $\left\{\begin{array}{l}0,77 \\
099\end{array}\right.$ & 1,2 & $\left\{\begin{array}{l}0,49 \\
0,56\end{array}\right.$ & $1,3\{$ & $\left\{\begin{array}{l}0,43 \\
0,48\end{array}\right.$ & 252,8 & 157,2 & 47,9 \\
\hline (12) & & (11) & & $(10)$ & & $(7)$ & & (5) & & (14) & (14) & (14) \\
\hline 3,5 & $\left\{\begin{array}{l}1,03 \\
1,28\end{array}\right.$ & 2,3 & $\left\{\begin{array}{l}0,84 \\
1,04\end{array}\right.$ & 1,8 & $\left\{\begin{array}{l}0,82 \\
0,94\end{array}\right.$ & 1,4 & $\left\{\begin{array}{l}0,56 \\
0,63\end{array}\right.$ & $1,4\{$ & $\left\{\begin{array}{l}0,56 \\
0,59\end{array}\right.$ & 329,2 & 168,0 & 51,3 \\
\hline (16) & & $(16)$ & & (14) & & (12) & & $(10)$ & & (15) & (16) & (16) \\
\hline 3,3 & $\left\{\begin{array}{l}1,09 \\
1,28\end{array}\right.$ & 2,0 & $\left\{\begin{array}{l}0,83 \\
1,02\end{array}\right.$ & 1,7 & $\left\{\begin{array}{l}0,81 \\
0,91\end{array}\right.$ & 1,2 & $\left\{\begin{array}{l}0,58 \\
0,67\end{array}\right.$ & $1,3\{$ & $\left\{\begin{array}{l}0,59 \\
0,68\end{array}\right.$ & 272,0 & 156,6 & 50,3 \\
\hline (14) & & $(15)$ & & $(10)$ & & (12) & & (9) & & (19) & (19) & (19) \\
\hline 4,1 & $\left\{\begin{array}{l}1,18 \\
1,33\end{array}\right.$ & 2,8 & $\left\{\begin{array}{l}0,98 \\
1,25\end{array}\right.$ & 2,1 & $\left\{\begin{array}{l}0,99 \\
10\end{array}\right.$ & 1,4 & $\left\{\begin{array}{l}0,61 \\
0775\end{array}\right.$ & $1,6\{$ & $\left\{\begin{array}{l}0,65 \\
086\end{array}\right.$ & 463,7 & 164,0 & 53,0 \\
\hline (11) & & (11) & & $(8)$ & & $(8)$ & & (8) & & (12) & (13) & (13) \\
\hline 3,5 & $\left\{\begin{array}{l}1,18 \\
1,36\end{array}\right.$ & 2,1 & $\{0,92$ & 1,7 & $\{0,93$ & 1,2 & $\{0,59$ & $1,3\}$ & $\{0,64$ & 308,0 & 154,0 & 45,2 \\
\hline (13) & & (13) & & (11) & & $(10)$ & & (6) & & (13) & (14) & (14) \\
\hline
\end{tabular}




\begin{tabular}{|c|c|c|c|c|c|c|c|c|c|}
\hline \multirow[t]{2}{*}{. } & & \multicolumn{2}{|c|}{ Art. Pulm. } & \multicolumn{2}{|c|}{$\begin{array}{l}\text { Aorta über } \\
\text { Klappen }\end{array}$} & \multicolumn{2}{|c|}{$\begin{array}{c}\text { Aorta } \\
\text { hinter } \\
\text { Bogen }\end{array}$} & \multicolumn{2}{|c|}{$\begin{array}{l}\text { Aorta an } \\
\text { Zwerch- } \\
\text { fell }\end{array}$} \\
\hline & & U. & D. & U. & D. & U. & D. & U. & D. \\
\hline \multirow{3}{*}{51 bis 60 Jahre } & (männlich & 7,9 & $\left\{\begin{array}{l}1,17 \\
1,37\end{array}\right.$ & 7,8 & $\left\{\begin{array}{l}1,72 \\
1,96\end{array}\right.$ & 6,0 & $\left\{\begin{array}{l}1,59 \\
1,74\end{array}\right.$ & $\begin{array}{l}5,7 \\
\end{array}$ & $\left\{\begin{array}{l}1,49 \\
1,64\end{array}\right.$ \\
\hline & & $(12$ & (13) & (13) & (1 77 & $(12)$ & (153 & (13) & $(1.42$ \\
\hline & weiblich & $\begin{array}{l}7,2 \\
(8)\end{array}$ & $\{1,41$ & $\begin{array}{l}7,3 \\
(9)\end{array}$ & $\{2,00$ & $\begin{array}{l}5,4 \\
(9)\end{array}$ & $\{1,66$ & $\begin{array}{l}5,2 \\
(8)\end{array}$ & $\{1,56$ \\
\hline \multirow[t]{2}{*}{61 bis 70 Jahre } & (männlich & $\begin{array}{r}7,9 \\
(11)\end{array}$ & $\left\{\begin{array}{l}1,12 \\
1,46\end{array}\right.$ & $\begin{array}{r}8,3 \\
(12)\end{array}$ & $\left\{\begin{array}{l}1,66 \\
2,01\end{array}\right.$ & $\begin{array}{r}6,6 \\
(12\end{array}$ & $\left\{\begin{array}{l}1,68 \\
1,88\end{array}\right.$ & $\begin{array}{r}6,0 \\
(10)\end{array}$ & $\left\{\begin{array}{l}1,50 \\
1,67\end{array}\right.$ \\
\hline & weiblich & $\begin{array}{r}7,5 \\
(7)\end{array}$ & $\left\{\begin{array}{l}1,19 \\
1,37\end{array}\right.$ & $\begin{array}{l}7,7 \\
(7)\end{array}$ & $\left\{\begin{array}{l}1,43 \\
1,72\end{array}\right.$ & $\begin{array}{l}5,7 \\
(7)\end{array}$ & $\left\{\begin{array}{l}1,52 \\
1,65\end{array}\right.$ & $\begin{array}{l}5,3 \\
(7)\end{array}$ & $\left\{\begin{array}{l}1,39 \\
1,44\end{array}\right.$ \\
\hline \multirow{2}{*}{71 bis 80 Jahre } & fännlich & $\begin{array}{l}7,0 \\
(5)\end{array}$ & $\begin{array}{c}1,14 \\
1,34 \\
(5)\end{array}$ & $\begin{array}{l}8,2 \\
(5)\end{array}$ & $\left\{\begin{array}{l}1,85 \\
2,05\end{array}\right.$ & $\begin{array}{l}6,7 \\
(4)\end{array}$ & $\left\{\begin{array}{l}1,61 \\
2,04\end{array}\right.$ & $\begin{array}{l}5,9 \\
(4)\end{array}$ & $\left\{\begin{array}{l}1,40 \\
1,66\end{array}\right.$ \\
\hline & & $\begin{array}{r}7,8 \\
(14\end{array}$ & $\left\{\begin{array}{l}1,17 \\
1,46\end{array}\right.$ & $\begin{array}{r}7,7 \\
(14)\end{array}$ & $\left\{\begin{array}{l}1,62 \\
1,84\end{array}\right.$ & 6,1 & $\left\{\begin{array}{l}1,66 \\
1,75\end{array}\right.$ & $\begin{array}{r}5,8 \\
\text { (19) }\end{array}$ & $\left\{\begin{array}{l}1,48 \\
1,65\end{array}\right.$ \\
\hline \multirow{2}{*}{ Ủber 81 Jahre } & männlich & $\begin{array}{l}8,1 \\
(3)\end{array}$ & $\left\{\begin{array}{l}1,19 \\
1,50\end{array}\right.$ & $\begin{array}{c}8,8 \\
(3)\end{array}$ & $\left\{\begin{array}{l}1,40 \\
1,94\end{array}\right.$ & $\begin{array}{l}6,7 \\
(2)\end{array}$ & $\left\{\begin{array}{l}1,65 \\
1,74\end{array}\right.$ & $\begin{array}{c}6,4 \\
(2)\end{array}$ & $\left\{\begin{array}{l}1,44 \\
1,70\end{array}\right.$ \\
\hline & $\begin{array}{l}\text { Weiblich } \\
\text { h abnorm }\end{array}$ & $\begin{array}{l}7,0 \\
(\mathbf{1})\end{array}$ & $\left\{\begin{array}{l}1,80 \\
2,00\end{array}\right.$ & $\begin{array}{l}7,5 \\
(1)\end{array}$ & $\left\{\begin{array}{l}2,40 \\
2,52\end{array}\right.$ & $\begin{array}{l}6,2 \\
(1)\end{array}$ & 1,94 & & \\
\hline
\end{tabular}

Jahren stark ab. Das Verhältnis von Lichtung zu Wanddicke ändert sich im Alter zu ungunsten der letzteren, aber nicht ganz gesetzmäßig; es ergibt bei den versehiedenen Geschlechtern in der Jugend annähernd gleiche Zahlen; im Alter wird die Verhältniszahl bei Frauen größer als bei Männern.

2. Arteria pulmonalis. Der Umfang der Pulmonalis unterliegt viel größeren individuellen Schwankungen. Wenn auch bezüglich des mit dem Alter stattfindenden Zuwachses im allgemeinen derselbe Modus gilt wie für die Aorta, so findet man doch auch gelegentlich schon in jungen Jahren auffallend dicke Wände. Bezüglich des Umfanges halten sich die Differenzen von den bei Männern und den bei Weibern ermittelten Zahlen mit zunehmendem Alter auf ziemlich gleicher Höhe; die Dickendifferenzen nehmen ab; vom 7. Dezennium an finden sich beim Weibe dickere Pulmonalwandungen. Utber das Verhältnis von Weite zu Dicke läßt sich bei der Ungesetzmäßigkeit der gefundenen Zahlen nur so viel sagen, daß der Bruchwert beim weiblichen Geschlecht mit den Jahren kleiner zu werden scheint und im Alter entschieden geringer ist als beim Manne.

Die mathematische Betrachtungsweise läßt uns aber weiterhin im Stich, weil die zahlreichen pathologischen Fälle hier nicht ausgeschieden sind und bei der großen Zahl von Fällen mit Herz- und Lungenkrankheiten, die in meinem Material mitaufgenommen sind, die Beeinflussung der Zahlen durch die abnormen Werte dieser Fälle möglich ist. Betrachtet man eine größere Anzahl solcher Fälle 


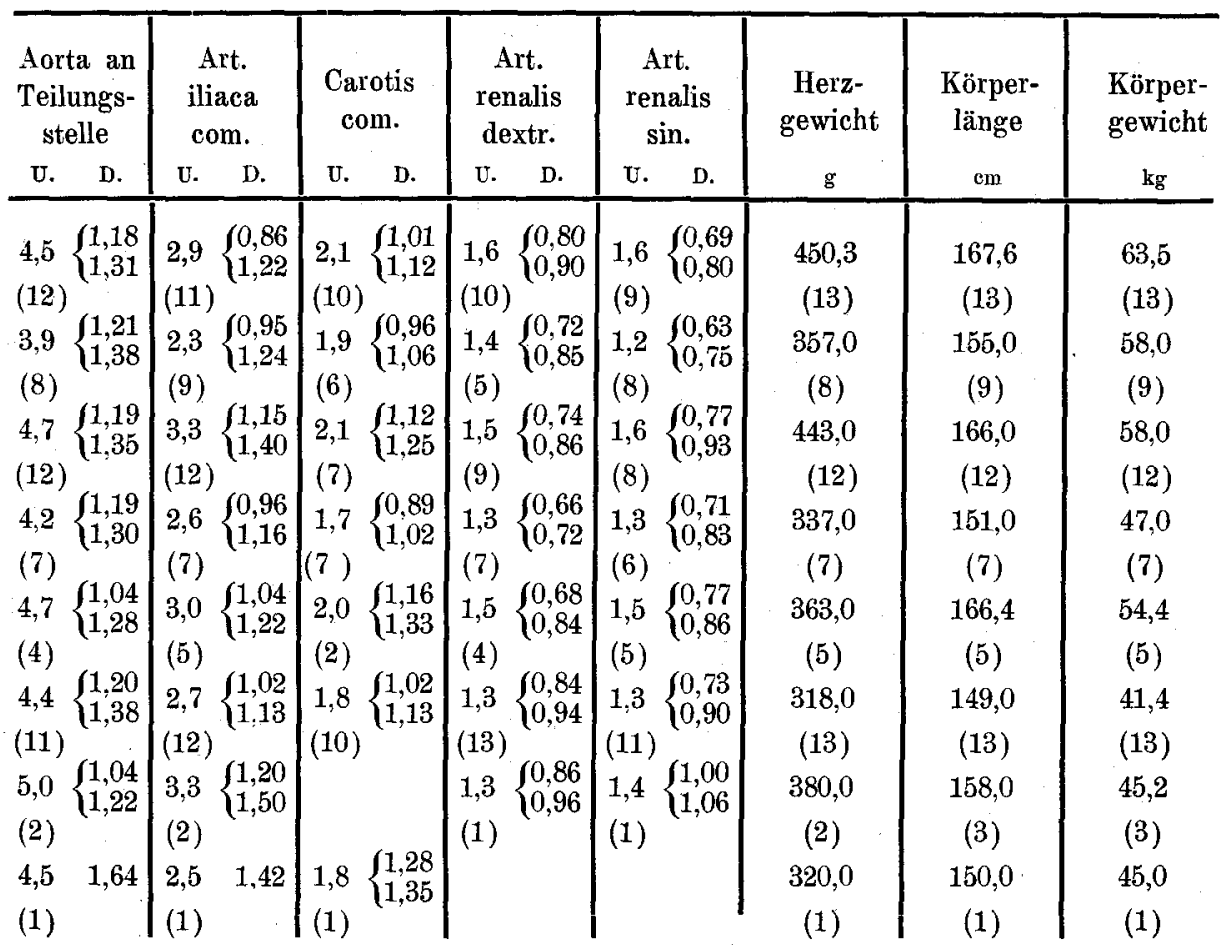

einzeln und vergleicht sie mit normalen Mittelwerten, so ergibt sich, daß eine kontinuierliche Erweiterung bis ins höchste Alter wie bei der Aorta bei der Pulmonalis nicht existiert. Daher kommt es, daß sie zwar bis ins 6. Dezennium weiter ist als die Aorta, daß sie aber dann hinter dieser zurückbleibt. Diese Beobachtung hat neuerdings auch $\mathrm{S}$ ch e e 1 wieder gemacht. Dies würde bedeuten, daß die die Elastizität der Gefäßje schwächenden Einflüsse die Pulmonalis nicht berühren, zumal die Tabelle ergibt, daß auch die Wandstärken im höheren Alter gleich bleiben. Man kann sich auch der Erfahrung nicht verschließen, daß in jüngerem Alter die Pulmonalis ganz besonders gut an mechanisch veränderte Verhältnisse sich anpaßt. (Das Nähere hierüber unten bei den mikroskopischen Untersuchungen.)

3. Arteria iliaca communis. Die Weite nimmt ständig zu vom ersten Jahre bis ins hohe Alter. Der Unterschied zwischen den Geschlechtern ist sehr bedeutend, und zwar absolut größer als bei der Aorta. Der Grund mag in der stärkeren Anstrengung der Beine von seiten des Mannes zu suchen sein. Die Zunahme der Wanddicke wächst im höheren Alter und verhält sich bei beiden Geschlechtern etwa gleich; sie basiert meistens auf starker Wucherung von längslaufenden Muskelfasern der Adventitia, worïber ich später genauer beriehten. werde. Das Verhältnis von Weite zu Dicke ergibt, wie überhaupt bei allen Gefäßen kleineren Kalibers, einen bedeutend niedrigeren Wert als bei Aorta und Pulmonalis. 
Es verschiebt sich im höheren Alter nur wenig noch weiter zugunsten der Wanddicke. Bezüglich der beiden Geschlechter finden sich in der Jugend annähernd gleiche Werte, während etwa vom 30. Lebensjahre an bei der jetzt rasch zunehmenden Differenz des Umfanges beim Manne höhere Verhältniszahlen zum Vorschein kommen als beim Weibe.

4. Carotis com $\mathrm{mun}$ is. Sie ist in den ersten Lebensjahren weiter und dicker als die Arteria iliaca communis. Ihre bis ins 6 . Jahrzehnt reichende Massenzunahme bleibt aber schon vom 10. Lebensjahr an hinter der der Iliaca zurück. Der Weiten- und Dickenunterschied zwischen den beiden Geschlechtern ist geringer als bei Aorta und Iliaca. Da die Zunahme beider Dimensionen bei Mann wie Weib von der Jugend bis zum Alter ziemlich gleichmäßige Fortschritte macht, stellt das Verhältnis von Umfang zu Dicke in jedem Alter und bei beiden Geschlechtern nahezu eine Konstante dar.

5. A r teri a r e n a lis. Die allmähliche Erweiterung mit dem Alter reicht etwa bis zum 6. Lebensjahrzehnt; dann wird das Lumen bei Mann wie Weib wieder etwas enger, ein Vorgang, der wohl mit der um diese Zeit schon beginnenden Atrophie der Nieren in Zusammenhang zu bringen ist. Die Wanddicke steigt auch mit dem Alter, ohne jedoch einen der Kaliberabnahme entsprechenden Rückgang zu zeigen; auch hierin verhalten sich die beiden Geschlechter gleich. Die Verhältniszahl Weite zu Dicke wird demnach vom 60. Lebensjahr an bedeutend kleiner.

Einflußder Körperlänge auf Gefäßweite und - dicke.

Eingangs erwähnte ich, daß ich bei meinen Messungen normaler Individuen auf die ja nicht überraschende Tatsache gestoßen war, daß große Individuen auch kräftig entwickelte, namentlich weite Gefäße besitzen.

B e ispiel. (Die Durchschnittswerte sind in Klammern beigefügt.) S.-Nr. 91/09. 30 jühriger Mann: Körperlänge $185 \mathrm{~cm}$. Tod durch Schädelbruch, Körpergewicht $64 \mathrm{~kg}$, Herzgewicht $370 \mathrm{~g}$. Als Durchschnitt erhielt ich aus etwa 20 Messungen bei Männern dieses Alters: Körperlänge 169,8 cm, Körpergewicht $52,1 \mathrm{~kg}$, Herzgewicht $342 \mathrm{~g}$.

GefäBmessungen:

\begin{tabular}{|c|c|c|c|c|}
\hline \multicolumn{5}{|c|}{ Gefäßmessungen: } \\
\hline & & fang & & icke \\
\hline Aorta über der Klappe & $7, \tilde{a}$ & $(5,9)$ & $\left\{\begin{array}{l}1,80 \\
2,08\end{array}\right.$ & $\begin{array}{l}(1,58) \\
(1,82)\end{array}$ \\
\hline Aorta hinter Bogen & 5,7 & $(4,7)$ & $\left\{\begin{array}{l}1,54 \\
1,70\end{array}\right.$ & $\begin{array}{l}(1,23) \\
(1,45)\end{array}$ \\
\hline Aorta am Zwerchfell & 5,0 & $(4,3)$ & $\left\{\begin{array}{l}1,54 \\
1,78\end{array}\right.$ & $\begin{array}{l}(1,21) \\
(1.30)\end{array}$ \\
\hline Aorta an Teilungsstelle & 4,0 & $(3,3)$ & $\left\{\begin{array}{l}1,26 \\
1,44\end{array}\right.$ & $\begin{array}{l}(1,09) \\
(1,26)\end{array}$ \\
\hline
\end{tabular}

Diese Zahlen überschreiten durchweg, und zwar ziemlich erheblich, meine für das betreffende Alter in der Tabelle II niedergelegten Mittelwerte. Um ein einigermaßen abschließendes und einwandfreies Urteil über den Einfluß der Körperlänge auf die Aorta- und übrigen Gefäßmaße fällen zu können, bedarf man eines sehr viel größeren Materials als das von mir untersuchte; denn nur solche Fälle kommen in Betracht, bei denen man berechtigterweise alle uns bekannten Ein- 
flüsse auf das Gefäßsystem ausschließen kann. Hiermit bin ich aber wieder auf meine Tabelle I (normale Gefäße) angewiesen. Ein Vergleich der Gefäße gleichaltriger, gleichgeschlechtlicher Individuen mit bedeutendem Unterschiede der Körperlänge ist natürlich aus diesem spärlichen Material nicht möglich. Ich kann daher nur einzelne Fälle (männlich über $1,70 \mathrm{~cm}$, unter 1,65 cm; weiblich über $1,60 \mathrm{~cm}$, unter $1,55 \mathrm{~cm}$ ) anführen und diesen die in der Tabelle II niedergelegten Durchschnittswerte meiner sämtlichen Messungen gegenüberstellen.

B e is p i e le. S.-Nr. 1123/08. 18 jähriger Mann, Todesursache: Hirntumor. Körperlänge 1,72 m, Körpergewicht $48 \mathrm{~kg}$, Herzgewicht $325 \mathrm{~g}$. Durchschnitt aus 6 Messungen bei Männern dieses Alters: Körperlänge $163,3 \mathrm{~cm}$, Körpergewicht $53,4 \mathrm{~kg}$, Herzgewicht 402,5 g.

\begin{tabular}{|c|c|c|c|c|}
\hline \multicolumn{5}{|c|}{ Gefäßmessungen: } \\
\hline rteria pulmonalis & 6,0 & $(5,6)$ & $\left\{\begin{array}{l}1,04 \\
1,40\end{array}\right.$ & $\begin{array}{l}(1,14) \\
(1,35)\end{array}$ \\
\hline orta über Klappe & 5,5 & $(5,2)$ & $\left\{\begin{array}{l}1,56 \\
1,78\end{array}\right.$ & $\begin{array}{l}(1,49) \\
(1,80)\end{array}$ \\
\hline orta hinter Bogen & 4,3 & $(4,3)$ & $\left\{\begin{array}{l}1,10 \\
1,50\end{array}\right.$ & $\begin{array}{l}(1,14) \\
(1,35)\end{array}$ \\
\hline Aorta am Zwerchfell & 4,0 & $(4,0)$ & $\left\{\begin{array}{l}1,26 \\
1,40\end{array}\right.$ & $\begin{array}{l}(1,15) \\
(1,32)\end{array}$ \\
\hline Aorta an Teilungsstelle & $\mathbf{3}, 0$ & $(2,9)$ & $\{1,28$ & $\begin{array}{l}(1,09) \\
(1,24)\end{array}$ \\
\hline Arteria iliaca com. & 2,1 & $(2,0)$ & 0,88 & $\begin{array}{l}(0,85) \\
(1,00)\end{array}$ \\
\hline Arteria rena & 1,3 & $(1,2)$ & $\left\{\begin{array}{l}0,54 \\
0,58\end{array}\right.$ & $\begin{array}{l}(0,54) \\
(0,60)\end{array}$ \\
\hline Arteria renalis sin. & 1,3 & $(1,2)$ & $\left\{\begin{array}{l}0,50 \\
0,66\end{array}\right.$ & $\begin{array}{l}(0,47) \\
(0,59)\end{array}$ \\
\hline
\end{tabular}

S.-Nr. 1095/08. 34 jähriger Mann, Tod durch Sturz aus der Höhe. Körperlänge 1,72 m, Körpergewicht $81 \mathrm{~kg}$, Herzgewicht $380 \mathrm{~g}$. Der Durchschnitt aus etwa 16 Messungen bei Männern dieses Alters beträgt: Körperlänge $168 \mathrm{~cm}$, Körpergewicht 51,3 kg, Herzgewicht 329,2 g.

\begin{tabular}{|c|c|c|c|c|}
\hline \multicolumn{5}{|c|}{ Gefäßmessungen: } \\
\hline Arteria pulmonalis & 8,5 & $(6,8)$ & $\left\{\begin{array}{l}1,04 \\
1,16\end{array}\right.$ & $\begin{array}{l}(0,92) \\
(1,18)\end{array}$ \\
\hline Aorta über Klappe & 6,5 & $(6,7)$ & $\{1,60$ & $\begin{array}{l}(1,62) \\
(1,83)\end{array}$ \\
\hline Aorta hinter Bogen & 5,3 & $(5,0)$ & $\left\{\begin{array}{l}1,40 \\
1,50\end{array}\right.$ & $\begin{array}{l}(1,33) \\
(1,54)\end{array}$ \\
\hline Aorta am Zwerchfell & 4,8 & $(4,6)$ & $\left\{\begin{array}{l}1,30 \\
1,40\end{array}\right.$ & $\begin{array}{l}(1,25) \\
(1,40)\end{array}$ \\
\hline Aorta an Teilungsstelle & 3,6 & $(3,5)$ & $\left\{\begin{array}{l}0,90 \\
1,02\end{array}\right.$ & $\begin{array}{l}(1,03) \\
(1,28)\end{array}$ \\
\hline Arteria iliaca com. & 2,8 & $(2,3)$ & $\left\{\begin{array}{l}0,80 \\
0,86\end{array}\right.$ & $\begin{array}{l}(0,84) \\
(1,04)\end{array}$ \\
\hline Carotis com. & 2,1 & $(1,8)$ & $\left\{\begin{array}{l}0,72 \\
0,80\end{array}\right.$ & $\begin{array}{l}(0,82) \\
(0.94)\end{array}$ \\
\hline Arteria renalis dextra & 1,4 & $(1,4)$ & $\{0,54$ & $\begin{array}{l}(0,56) \\
(0,63)\end{array}$ \\
\hline Arteria renalis sin. & 1,6 & $(1,4)$ & $\{0,48$ & $\begin{array}{l}(0,56) \\
(0,59)\end{array}$ \\
\hline
\end{tabular}


S.-Nr. 964/08. 54 jähriger Mann. Tod durch Verletzung. Körperlänge 1,75 m, Körpergewicht $72 \mathrm{~kg}$, Herzgewicht $340 \mathrm{~g}$. Durchschnitt aus 13 Messungen bei Männern dieses Alters: Körperlänge $167,6 \mathrm{~cm}$, Körpergewicht $63,5 \mathrm{~kg}$, Herzgewicht $450,3 \mathrm{~g}$.

\begin{tabular}{|c|c|c|c|c|}
\hline \multicolumn{5}{|c|}{ Gefäßmessungen: } \\
\hline Aorta über Klappe & 8,1 & $(7,8)$ & $\left\{\begin{array}{l}2,00 \\
2,10\end{array}\right.$ & $\begin{array}{l}(1,72) \\
(1,96)\end{array}$ \\
\hline Aorta hinter Bogen & 6,0 & $(6,0)$ & $\left\{\begin{array}{l}1,65 \\
1,72\end{array}\right.$ & $\begin{array}{l}(1,59) \\
(1,74)\end{array}$ \\
\hline Aorta am Zwerchfell & 5,5 & $(5,7)$ & $\left\{\begin{array}{l}1,46 \\
1,50\end{array}\right.$ & $\begin{array}{l}(1,49) \\
(1,64)\end{array}$ \\
\hline Aorta an Teilungsstelle & 4,2 & $(\mathbf{4}, \mathbf{5})$ & $\{1,40$ & $\begin{array}{l}(1,18) \\
(1,31)\end{array}$ \\
\hline Arteria iliaca com. & 2,7 & $(2,9)$ & $\left\{\begin{array}{l}1,08 \\
1,10\end{array}\right.$ & $\begin{array}{l}(0,86) \\
(1,22)\end{array}$ \\
\hline Carotis com. & 2,6 & $(2,1)$ & $\left\{\begin{array}{l}1,02 \\
1,10\end{array}\right.$ & $\begin{array}{l}(1,01) \\
(1,12)\end{array}$ \\
\hline Arteria renalis dextra & 1,8 & $(1,6)$ & $\{0,60$ & $\begin{array}{l}(0,80) \\
(0,90)\end{array}$ \\
\hline Arteria ren: & 1,7 & $(1,6)$ & $\left\{\begin{array}{l}0,70 \\
0,74\end{array}\right.$ & $\begin{array}{l}(0,69) \\
(0,80)\end{array}$ \\
\hline
\end{tabular}

S.-Nr. 279/09. 21 jähriger Mann. Tod durch Bruch der Wirbelsäule. Körperlänge 1,64 m, Körpergewicht $62 \mathrm{~kg}$, Herzgewicht $410 \mathrm{~g}$. Durchschnitt aus 4 Messungen bei Männern dieses Alters: Körperlänge $165 \mathrm{~cm}$, Körpergewicht $58,5 \mathrm{~kg}$, Herzgewicht $427,5 \mathrm{~g}$.

\section{Gefäßmessungen :}

\begin{tabular}{|c|c|c|c|c|}
\hline \multirow[b]{2}{*}{ Arteria pulmonalis } & \multicolumn{2}{|c|}{ Umfang } & \multicolumn{2}{|c|}{ Dicke } \\
\hline & 6,2 & $(6,7)$ & $\left\{\begin{array}{l}1,04 \\
1,40\end{array}\right.$ & $\begin{array}{l}(1,11) \\
(1,44)\end{array}$ \\
\hline Aorta über Klappe & 5,9 & $(5,7)$ & $\left\{\begin{array}{l}1,60 \\
1,76\end{array}\right.$ & $\begin{array}{l}(1,54) \\
(1,82)\end{array}$ \\
\hline Aorta hinter Bogen & 4,8 & $(4,4)$ & $\left\{\begin{array}{l}1,00 \\
1,36\end{array}\right.$ & $\begin{array}{l}(1,05) \\
(1,36)\end{array}$ \\
\hline Aorta am Zwerchfell & 4,3 & $(4,0)$ & $\left\{\begin{array}{l}0,96 \\
1,20\end{array}\right.$ & $\begin{array}{l}(1,05) \\
(1,23)\end{array}$ \\
\hline Aorta an Teilungsstelle & 3,2 & $(3,1)$ & $\left\{\begin{array}{l}0,98 \\
1,14\end{array}\right.$ & $\begin{array}{l}(1,04) \\
(1,24)\end{array}$ \\
\hline Arteria iliaca com. & 2,1 & $(2,2)$ & $\left\{\begin{array}{l}0,76 \\
1,06\end{array}\right.$ & $\begin{array}{l}(0,83) \\
(1,03)\end{array}$ \\
\hline Arteria renalis dextra & 1,2 & $(1,3)$ & $\left\{\begin{array}{c}0,56 \\
0,66\end{array}\right.$ & $\begin{array}{l}(0,50) \\
(0,57)\end{array}$ \\
\hline Arteria renalis sin & 1,2 & $(1,3)$ & thror & posiert \\
\hline
\end{tabular}

S.-Nr. 214/09. 34 jähriger Mann, Todesursache: Apoplexie der rechten Großhirnhemisphäre ohne Arteriosklerose. Körperlänge $1,53 \mathrm{~m}$, Körpergewicht $49 \mathrm{~kg}$, Herzgewicht $325 \mathrm{~g}$. Durchschnitt aus etwa 16 Messungen bei Männern dieses Alters: Körperlänge $168 \mathrm{~cm}$, Körpergewicht $51,3 \mathrm{~kg}$, Herzgewicht $329,2 \mathrm{~g}$.

\begin{tabular}{|c|c|c|c|}
\hline \multicolumn{4}{|c|}{ Gefäßmessungen: } \\
\hline Arteria pulmonalis & $6,5 \quad(6,8)$ & $\left\{\begin{array}{l}0,96 \\
1,16\end{array}\right.$ & $\begin{array}{l}(0,92) \\
(1,18)\end{array}$ \\
\hline Aorta über Klappe & $6,3 \quad(6,7)$ & $\left\{\begin{array}{l}1,66 \\
2.00\end{array}\right.$ & $\begin{array}{l}(1,62) \\
(1,83)\end{array}$ \\
\hline
\end{tabular}




\begin{tabular}{|c|c|c|c|c|}
\hline Aorta hinter Bogen & 4,8 & $(5,0)$ & $\left\{\begin{array}{l}1,56 \\
1,76\end{array}\right.$ & $\begin{array}{l}(1,33) \\
(1,54)\end{array}$ \\
\hline Aorta am Zwerchfell & 4,4 & $(4,6)$ & $\left\{\begin{array}{l}1,44 \\
1,70\end{array}\right.$ & $\begin{array}{l}(1,25) \\
(1,40)\end{array}$ \\
\hline Aorta an Teilungsstelle & 3,5 & $(3, \tilde{\mathbf{a}})$ & $\left\{\begin{array}{l}1,28 \\
1,56 \\
1,70\end{array}\right.$ & $\begin{array}{l}(1,03) \\
(1,28)\end{array}$ \\
\hline Arteria iliaca com. & 2,5 & $(2,3)$ & $\left\{\begin{array}{l}0,90 \\
1,10 \\
1,40\end{array}\right.$ & $\begin{array}{l}(0,84) \\
(1,04)\end{array}$ \\
\hline Arteria renalis dextra & 1,5 & $(1,4)$ & $\left\{\begin{array}{l}0,70 \\
0,80\end{array}\right.$ & $\begin{array}{l}(0,56) \\
(0,63)\end{array}$ \\
\hline
\end{tabular}

S.-Nr. 233/09. Weib, 22 Jahre. Todesursache: Sepsis, ausgehend von diffuser eitriger Peritonitis. Körperlänge 1,61 m, Körpergewicht $47 \mathrm{~kg}$, Herzgewicht $335 \mathrm{~g}$. Durchschnitt aus 7 Messungen bei Weibern dieses Alters: Körperlänge $161,1 \mathrm{~cm}$, Körpergewicht $44,7 \mathrm{~kg}$, Herzgewicht $250 \mathrm{~g}$.

\begin{tabular}{|c|c|c|c|c|}
\hline \multicolumn{5}{|c|}{ Gefäßmessungen : } \\
\hline Arteria pulmonalis & 5,5 & $(6,2)$ & $\left\{\begin{array}{l}0,92 \\
1,02\end{array}\right.$ & $\begin{array}{l}(0,82) \\
(1,10)\end{array}$ \\
\hline Aorta über Klappe & 5,5 & $(5,5)$ & $\left\{\begin{array}{l}1,66 \\
1,90\end{array}\right.$ & $\begin{array}{l}(1,34) \\
(1,63)\end{array}$ \\
\hline Aorta hinter Bogen & 4,3 & $(4,3)$ & $\left\{\begin{array}{l}1,14 \\
1,30\end{array}\right.$ & $\begin{array}{l}(1,01) \\
(1,21)\end{array}$ \\
\hline Aorta am Zwerchfell & 3,9 & $(3,9)$ & $\left\{\begin{array}{l}1,18 \\
1,30\end{array}\right.$ & $\begin{array}{l}(1,03) \\
(1,20)\end{array}$ \\
\hline Aorta an Teilungsstelle & 3,1 & $(2,9)$ & $\left\{\begin{array}{l}1,04 \\
1,36\end{array}\right.$ & $\begin{array}{l}(0,94) \\
(1,22)\end{array}$ \\
\hline Arteria iliaca com. & 2,0 & $(1,9)$ & $\left\{\begin{array}{l}0,76 \\
1,04\end{array}\right.$ & $\begin{array}{c}(0,80) \\
(0,99)\end{array}$ \\
\hline
\end{tabular}

S.-Nr. 528/09. Weib, 14 Jahre. Tod durch Erschießen. Körperlänge 1,61 m, Körpergewicht $49 \mathrm{~kg}$, Herzgewicht $260 \mathrm{~g}$. Durehschnitt aus 3 Messungen bei Weibern dieses Alters: Körperlänge $143,6 \mathrm{~cm}$, Körpergewicht $33,1 \mathrm{~kg}$, Herzgewicht $223 \mathrm{~g}$.

\section{Gefäßmessungen:}

Umfang Dicke

Arteria pulmonalis

$6,0 \quad(5,2) \begin{cases}0,90 & (0,78) \\ 1,04 & \\ 1,24 & (1,08)\end{cases}$

Aorta über Klappe

$5,5 \quad(4,9) \begin{cases}1,42 & (1,24) \\ 1,56 & (1,56)\end{cases}$

Aorta hinter Bogen

$4,1 \quad(3,8) \begin{cases}1,04 & (0,75) \\ 1,24 & (1,17)\end{cases}$

Aorta am Zwerchfell

$3,8 \quad(3,4) \begin{cases}1,04 & (0,88) \\ 1,18 & (1,05)\end{cases}$

Aorta an Teilungsstelle

$2,7(2,5) \begin{cases}0,80 & (0,92) \\ 1,00 & (1,12)\end{cases}$

Arteria iliaca com.

$1,8 \quad(1,7) \begin{cases}0,70 & (0,64) \\ 0,80 & (0,86)\end{cases}$

Arteria renalis dextra

$1,3 \quad(1,2) \begin{cases}0,50 & (0,45) \\ (0,50)\end{cases}$

Arteria renalis sin.

$1,3 \quad(1,2) \begin{cases}0,56 & (0,64) \\ 0.66 & (0,72)\end{cases}$

S. Nr. 1007/08. Weib, 23 Jahre. Todesursache: eitrige Leptomeningitis. Körperlänge $1,50 \mathrm{~m}$, Körpergewicht $47 \mathrm{~kg}$, Herzgewicht $270 \mathrm{~g}$. Durchschnitt aus 14 Messungen bei Weibern dieses Alters: Körperlänge 157,2 cm, Körpergewicht 47,9 kg, Herzgewicht 252,8. 
Gefäßmessungen:

\begin{tabular}{|c|c|c|c|c|}
\hline \multirow[b]{2}{*}{ Arteria pulmonalis } & \multicolumn{2}{|c|}{ Umfang } & \multicolumn{2}{|c|}{ Dicke } \\
\hline & 6,0 & $(6,2)$ & $\left\{\begin{array}{l}0,98 \\
1,38\end{array}\right.$ & $\begin{array}{l}(0,92) \\
(1,16)\end{array}$ \\
\hline Aorta über Klappe & 6,0 & $(5,5)$ & $\left\{\begin{array}{l}1,66 \\
1,72\end{array}\right.$ & $\begin{array}{l}(1,42) \\
(1,65)\end{array}$ \\
\hline Aorta hinter Bogen & 4,0 & $(4,4)$ & $\left\{\begin{array}{l}1,26 \\
1,34\end{array}\right.$ & $\begin{array}{l}(1,18) \\
(1,33)\end{array}$ \\
\hline Aorta am Zwerchfell & 4,0 & $(4,1)$ & $\{1,24$ & $\begin{array}{l}(1,07) \\
(1,21)\end{array}$ \\
\hline Aorta an Teilungsstelle & 3,0 & $(3.0)$ & $\left\{\begin{array}{l}0,90 \\
1,30\end{array}\right.$ & $\begin{array}{l}(1,00) \\
(1,18)\end{array}$ \\
\hline Carotis com. & 1,5 & $(1,7)$ & $\left\{\begin{array}{l}0,85 \\
0,94\end{array}\right.$ & $\begin{array}{l}(0,77) \\
(0,99)\end{array}$ \\
\hline
\end{tabular}

S.-Nr. 106/09. Weib, 43 Jahre. Tod durch Schädelbruch. Körperlänge 1,47 m, Körpergewicht $50 \mathrm{~kg}$, Herzgewicht $280 \mathrm{~g}$. Durchschnitt aus etwa 14 Messungen bei Weibern dieses Alters: Körperlänge $154 \mathrm{~cm}$, Körpergewicht $45,2 \mathrm{~kg}$, Herzgewicht $308 \mathrm{~g}$.

Gefäßmessungen:

$$
\text { Umfang Dicke }
$$

\begin{tabular}{|c|c|c|c|c|}
\hline Arteria pulmonalis & 7,0 & $(7,3)$ & $\left\{\begin{array}{l}1,00 \\
1,18\end{array}\right.$ & \\
\hline Aorta über Klappe & 6,5 & $(6,8)$ & $\left\{\begin{array}{l}1,70 \\
1,90\end{array}\right.$ & \\
\hline Aorta hinter Bogen & 4,8 & $(5,1)$ & $\left\{\begin{array}{l}1,24 \\
1,52\end{array}\right.$ & \\
\hline Aorta am Zwerchfell & 4,3 & $(4,6)$ & $\left\{\begin{array}{l}1,18 \\
1,44\end{array}\right.$ & \\
\hline Aorta an Teilungsstelle & 3,6 & $(3,5)$ & $\left\{\begin{array}{l}1,12 \\
1,28\end{array}\right.$ & \\
\hline Arteria iliaca com. & 2,2 & $(2,1)$ & $\left\{\begin{array}{l}0,76 \\
0,80\end{array}\right.$ & \\
\hline
\end{tabular}

Von Interesse dürfte eine Gegenüberstellung der gleichaltrigen Fälle: S.-Nr. 1095/08, 34 jähriger Mann, Körperlänge 1,72 m und S.-Nr. 214/09, 34 jähriger Mann, Körperlänge 1,63 m, sein.

\section{Gefäßmessungen:}

Umfang

$\begin{array}{llll}\text { S. N. } 1095 & \text { S. N. } 214 & \text { S. N. } 1095 & \text { S. N. } 214\end{array}$

\begin{tabular}{|c|c|c|c|c|}
\hline Arteria pulmonalis & 8,5 & 6,5 & $\left\{\begin{array}{l}1,04 \\
1,16\end{array}\right.$ & $\begin{array}{l}0,96 \\
1,16\end{array}$ \\
\hline Aorta über Klappe & 6,5 & 6,3 & 1,60 & $\left\{\begin{array}{l}1,66 \\
2,00\end{array}\right.$ \\
\hline Aorta hinter Bogen & 5,3 & 4,8 & $\left\{\begin{array}{l}1,40 \\
1,50\end{array}\right.$ & $\begin{array}{l}1,56 \\
1,76\end{array}$ \\
\hline Aorta am Zwerchfell & 4,8 & 4,4 & $\left\{\begin{array}{l}1,30 \\
1,40\end{array}\right.$ & $\begin{array}{l}1,44 \\
1,70\end{array}$ \\
\hline Aorta an Teilungsstelle & 3,6 & 3,5 & $\left\{\begin{array}{l}0,90 \\
1,02\end{array}\right.$ & $\begin{array}{l}1,28 \\
1,56 \\
1,70\end{array}$ \\
\hline Iliaca communis & 2,8 & 2,5 & $\left\{\begin{array}{l}0,80 \\
0,86\end{array}\right.$ & $\begin{array}{l}0,90 \\
1,10 \\
1,40\end{array}$ \\
\hline Carotis communis & 2,1 & & $\left\{\begin{array}{l}0,72 \\
0,80\end{array}\right.$ & \\
\hline Arteria renalis dextra & 1,4 & 1,5 & 0,54 & $\left\{\begin{array}{l}0,70 \\
0,80\end{array}\right.$ \\
\hline Arteria renalis sin. & 1,6 & & 0,48 & \\
\hline
\end{tabular}


Die Beispiele mit den Durchschnittszahlen als Vergleich ergeben keine durchaus konstante Proportion von Körpergröße und Gefäßweite. Am meisten noch scheint die Arteria pulmonalis der Körperlänge zu folgen. Die Gegenüberstellung der Fälle S.-Nr. 1095/08 und S.-Nr. 214/09 ergibt allerdings bei dem um fast $20 \mathrm{~cm}$ größeren Manne durchweg höhere Umfangszahlen. Vollkommen unbeeinflußt bleibt offenbar die Gefäßwanddicke. Die auffallend dickwandigen Gefäße des schon mehrfach erwähnten Falles S.-Nr. 91/09, 30 jähriger Mann, stellen offenbar eine Abnormität dar. Diesen Schluß halte ich für um so berechtigter, als ich wie ich nicht verschweigen will - hin und wieder auch bei kleinen Individuen recht große Aortenmaße fand.

B e i s p i e l. S.-Nr. 53/09. 26 jähriger Mann. Todesursache: Erysipel. Körperlänge $1,62 \mathrm{~m}$, Körpergewieht $50,5 \mathrm{~kg}$, Herzgewicht $245 \mathrm{~g}$.

\begin{tabular}{|c|c|c|c|c|}
\hline Gefäß & $\begin{array}{l}\text { Unge } \\
\text { Um }\end{array}$ & $\begin{array}{l}\text { a: } \\
\text { fang }\end{array}$ & & cke \\
\hline Aorta über Klappe & 5,8 & $(5,7)$ & $\left\{\begin{array}{l}1,30 \\
1,44 \\
1,64\end{array}\right.$ & $\begin{array}{l}(1,65) \\
(1,87)\end{array}$ \\
\hline Aorta hinter Bogen & 5,2 & $(4,7)$ & $\left\{\begin{array}{l}1,24 \\
1,37\end{array}\right.$ & $\begin{array}{l}(1,27) \\
(1,57)\end{array}$ \\
\hline Aorta über Zwerchfell & 4,7 & $(4,2)$ & $\left\{\begin{array}{l}1,28 \\
1,34\end{array}\right.$ & $\begin{array}{l}(1,24) \\
(1,36)\end{array}$ \\
\hline Aorta an Teilungsstelle & 3,4 & $(3,3)$ & $\left\{\begin{array}{l}1,02 \\
1,12 \\
1,20\end{array}\right.$ & $\begin{array}{l}(1,08) \\
(1,25)\end{array}$ \\
\hline
\end{tabular}

Ein Versuch, eine Beziehung zwischen Gefäßgröße und Körpergewicht zu finden, hat für die Gesamtheit der Fälle wenig Wert, da durch langdauernde Krankheiten und durch Unterernährung das Verhältnis verschoben und unberechenbar wird; es können höchstens rasch gestorbene, bis kurz vor dem Tode gesunde und richtig ernährte Personen zur Bearbeitung jener Relation verwendet werden; in unserem in dieser Hinsicht sehr spärlichen Material hat sich eine gesetzmäßige Beziehung zwischen Gefäß- und Körpergewichtswerten nicht ausfindig machen lassen.

\section{A ortage wicht.}

Meine Aortawägungen ergaben das schon vermutete Bestehen einer vollkommenen Proportion zwischen Gewicht und Wanddicke; dünnwandige Aorten haben natürlich niedriges Gewicht; dickwandige Aorten hohes Gewicht. Es geht jedoch bemerkenswerterweise auch aus ihnen hervor, daß die Aortawand nicht der allgemeinen Altersatrophie verfällt, ebensowenig wie eine Relation mit der Körperlänge existiert. Das normale Gewicht für $25 \mathrm{qcm}$ Aorta beim Erwachsenen schwankt zwischen 4,25 und 5,0 g. Über das Verhältnis von Aortagewicht zu Herzgewicht soll vorerst nur bemerkt werden, daß sich hier ziemlich gesetzmäßig, ich möchte sagen reziproke Werte finden; mit andern Worten: das Aortagewicht ist bei schweren Herzen relativ gering, bei leichten Herzen relativ hoch. 


\section{Mikroskopische Messungen.}

Meine mikroskopischen Messungen, die mir in erster Linie darüber Aufschluß geben sollten, in welcher Weise bei $\mathrm{Zu}$ - und Abnahme der gesamten Wanddicke sich die einzelnen Schichten beteiligen, erstreckten sich auf die Aorta (über der Klappe, hinter dem Bogen, über dem Zwerchfell), auf die Arteria iliaca communis, Arteria renalis und Arteria pulmonalis.

A orta über der Klappe: Die physiologischen Differenzen der Intima-Ausbildung sind jüngst wieder von $\mathrm{A}$. A s $\mathrm{ch}$ of $\mathrm{f}$ hervorgehoben worden. Auf die übrige Literatur kann hier nicht eingegangen werden. Nach meinen eigenen Untersuchungen ist die Intima bis zum 2., manchmal 3. Dezennium ziemlich dünn, sie mißt 0,0185 bis $0,037 \mathrm{~mm}$, an manchen Stellen bis $0,0925 \mathrm{~mm}$. Im 4 . und 5 . Dezennium schwanken die Mittelwerte zwischen 0,0555 und $0,0925 \mathrm{~mm}$ (manchmal bis 0,185 ). Im Alter ist die Intima 0,0925 bis $0,185 \mathrm{~mm}$ dick, übertrifft demnach die in der Jugend befundenen Mittelwerte um das Fünf- bis Sechsfache. Die physiologisch ,dicke Intima" des Alters besteht bekanntlich, wenn wir mit J o r e s zweckmäßig einteilen, aus einer unter dem Fndothel gelegenen innersten Bindegewebslage, einer mittleren elastischen Faserschicht und einer, wie ich glaube, nicht immer mit muskulösen Elementen durchsetzten weiteren elastischen Schicht (elastisch-muskulöse Längsschicht von $\mathrm{J}$ or e s ).

Die Media stellt die Hauptschicht der Wand dar, und es sind die physiologischen (Alters- und Geschlechts-) Schwankungen der Gesamtdicke im wesentlichen auf ihr Konto zu setzen. Von der Adventitia sieht man nach Entfernung des groben Bindegewebes mittels Schere im mikroskopischen Präparat nur mehr ganz geringe Reste. Dies war wichtig festzustellen, um uns über die Zuverlässigkeit unserer Methode zu vergewissern, bei der wir ja das sukkulente Adventitiagewebe, welehes nach außen keine Grenze hat, entfernen mußten. Es ist schon bemerkt worden, daß es Fälle gibt, in denen die Adventitia nicht in so befriedigender Weise abpräpariert werden kann. Dies ist insbesondere bei syphilitischer Entzündung der Gefäßwand der Fall.

In der absteigenden Brustaorta ergaben die mikroskopischen Messungen der Intima viel höhere Zahlen als über der Klappe (im Mittel 0,185 bis 0,370). Die Media erscheint dagegen verhältnismäßig schwach.

Die Intimamessung an der A r terià iliac a communis ergibt oft schon in der Jugend stellenweise verhältnismäßig große Zahlen. Mit dem vorrückenden Alter scheint diese Schicht jedoch keine wesentlichere Verbreiterung zu erfahren. Schon in der Jugend finden sich stellenweise starke Verdickungen ohne fettige Degeneration, während die zirkumskripten Verdickungen im Alter meist auf fettige Degeneration und kalkige Auflagerungen zurückzuführen sind. Während die Gesamtdicke der Iliaca mit dem Alter eine ständige Zunahme erfährt, hält sich auch die Dicke der Media auf ziemlich konstanter Höhe; ab und zu fand ich sie im höheren Alter sogar verschmälert, jedoch nur an Stellen, wo dann die 


\begin{tabular}{|c|c|c|c|c|c|c|c|}
\hline & N. & $\begin{array}{c}\text { Ge- } \\
\text { schlecht }\end{array}$ & $\begin{array}{l}\text { Intima } \\
\text { Media }\end{array}$ & $\begin{array}{c}\text { Intima- } \\
\text { dicke }\end{array}$ & $\begin{array}{l}\text { Media- } \\
\text { dicke }\end{array}$ & $\begin{array}{l}\text { Intima: } \\
\text { Media }\end{array}$ & \\
\hline & $997 / 08$ & Mann 18 & 1,59 & 0,0185 & 1,57 & & Epilepsie \\
\hline : & $1.165 / 08$ & Mann 26 & 1,64 & 0,0185 & 1,62 & & Idiopath. Herz- \\
\hline 要 & $73 / 09$ & Weib 21 & 1,13 & 0,0185 & 1,110 & & Sepsis \\
\hline$\overline{0} \approx$ & $1007 / 08$ & Weib 23 & 1,33 & 0,0370 & 1,295 & & $\begin{array}{l}\text { Eitrige Menin- } \\
\text { gitis }\end{array}$ \\
\hline & $\begin{array}{c}\text { Mittel- } \\
\text { zahl }\end{array}$ & & 1,42 . & 0,0241 & 1,398 & $\frac{1,72}{100}$ & \\
\hline & $1077 / 08$ & Mann 26 & 1,27 & 0,074 & 1,20 & & Peritonitis \\
\hline 焉焉 & $1007 / 08$ & Weib 23 & 1,05 & 0,074 & 0,9805 & & Eitrige Menin- \\
\hline & $1070 / 08$ & Weib 26 & 1,10 & 0,037 & 1,063 & & Peritonitis \\
\hline & $\begin{array}{l}\text { Mittel- } \\
\text { zahl }\end{array}$ & & 1,14 & 0,0616 & 1,081 & $\begin{array}{l}5,69 \\
100\end{array}$ & \\
\hline
\end{tabular}

Intima gewuchert erschien. Bei meinen makroskopischen Messungen fiel mir nicht selten eine blaßrot gefärbte Verdickung der Adventitia auf. Das Mikroskop zeigte, daß diese Verdickungen auf eine reichliche Wucherung von längslaufenden Muskelfasern zurückzuführen sind. Obwohl normalerweise bloß geringe längslaufende Muskelfasern in der Adventitia vorhanden sind, möchte ich doch diese vermehrten längslaufenden Muskelbündel vorzüglich bei Männern des höheren Alters - in der Jugend sind sie, namentlich bei Frauen, sehr selten - nicht durchweg zu den pathologischen Befunden zählen. Im übrigen besitzt die liaca eine besonders dicht gewebte Adventitia; gleichwohl läßt sie sich zwecks Messungen ganz gut abpräparieren.

Arteria renalis: Wenn meine Messungen an der Nierenarterie auch nicht sehr zahlreich sind, so kann ich doch immerhin einige Resultate mitteilen. Die Intimadicke variiert normalerweise in ziemlich weiten Grenzen. Das Alter scheint auf die Intimadicke ohne Einfluß zu sein; dagegen begegnet man bei Männern durchschnittlich höheren Zahlen als bei Frauen. Die Media ist ziemlich schwach. Ein Verhältnis zu Alter und Geschlecht konnte ich nicht wahrnehmen. Die Adventitia erwies sich fast stets, trotz sorgfältigster Entfernung des groben Bindegewebes, als ziemlich dicke Schicht $(0,0925$ bis 0,2775 , manchmal noch höher), mit dichter Struktur und reichlichen elastischen Fasern. Nicht selten sah ich Wucherungen der querlaufenden Muskelfasern, manchmal auch mäßige der längslaufenden.

Pulmonalis. Wie schon erwähnt, unterliegt die Wanddicke der Pulmonalis großen individuellen Schwankungen, die ich auf die starke Anpassungsfähigkeit dieses Gefäßes bei chronischen Herz- und Lungenkrankheiten zurückführen zu müssen glaube; wenigstens sprechen dafür die bei Kindern mit Herzkrankheiten usw. gefundenen hohen Zahlen und der Umstand, daß alte Leute mit gesunden Lungen und normalem Herzen verhältnismäßig dünne Pulmonalwandun- 
gen haben, während die häufig vorkommende dicke Wand im Alter mit dem Altersemphysem in Zusammenhang zu bringen ist. Mikroskopisch beruht die Dickenzunahme hauptsächlich auf Hypertrophie der Media. Die Intima ist im Vergleich dazu meist weniger verdickt. Dabei fehlt fettige Degeneration ganz oder ist nur sehr gering, selbst wenn die Intima der kleinen Lungenarterien bereits halbmondförmig verdickt und fettig degeneriert ist.

Relative Umfangs-und Dickenzahlen, bezogen auf die A orta überdem $\mathrm{Z}$ werchfell.

Es schien mir von Wichtigkeit, die Dicken- und Weitenverhältnisse verschiedener Gefäße oder eines Gefäßes in verschiedener Höhe bei dem gleichen Individuum einerseits, die Verhältnisse der gleichen Gefäße oder eines Gefäßes in gleicher Höhe bei verschiedenen Individuen andererseits in Wechselbeziehung zueinander zu bringen. Ich ging hierbei von den in Tabelle II nach Alter und Geschlecht registrierten Mittelwerten (bei der Dicke Mittelwert aus den Doppelmessungen) der Aorta am Zwerchfell als Einheit aus, da gerade die Aorta an dieser Stelle verhältnismäßig geringen individuellen Weiten- und Dickenschwankungen unterworfen ist. Ich fand bei diesen Untersuchungen:

Die Umfänge der Aorta am Zwerchfell, hinter dem Bogen und an der Teilungs stelle stehen im Verhältnis von 1,00:1,07: 0,74. Diese Zahlen kehren in jeder Altersgruppe und bei den Geschlechtern mit ziemlicher Konstanz wieder. Weniger gesetzmäßig verhält sich die Aorta über der Klappe, deren relativer Umfang, auf die Aorta am Zwerchfell berechnet, im Durchschnitt 1,41 (bei Kindern etwas mehr, im Alter etwas weniger) beträgt, und der relative Umfang der Pulmonalis, der auch in der Jugend höhere Werte erreicht als im späteren Leben.

Für das Lumen der lliaca communis ergibt sich als Durchschnittsrelation die Zahl 0,49; doch finden sich in Utbereinstimmung mit meiner schon erwähnten Beobachtung von den bedeutenden Weitendifferenzen zwischen den beiden Geschlechtern bei Frauen stets niedrigere Werte als bei Männern.

Der relative Umfang der Carotis communis wird im Laufe des Lebens ständig kleiner; er beträgt im 1. bis 2. Jahre 0,54, im Alter von 71 bis 80 Jahren 0,37 . Ein Unterschied der Geschlechter besteht nicht.

Hinsichtlich der Dicke stehen in nahezu konstantem Verhältnis zur Aorta am Zwerchfell nur die Aorta hinter dem Bogen $(1,00: 1,07)$ und die Tliaca communis $(1,00: 0,77)$.

Die relative Dicke der Aorta über der Klappe (Durchschnitt 1,32), der Aorta an der Teilungsstelle (Durchsehnitt 0,92) und der Carotis communis (Durchschnitt 0,73 ) ist stets in der Jugend größer als im Alter, d. h. die physiologischen Dickenunterschiede an verschiedenen Stellen und zwischen Aorta und den genannten Ästen nivellieren sich mit dem Alter.

Die Relationszahlen der Pulmonalwand ergeben unregelmäßige Werte, sinken aber im allgemeinen auch mit dem zunehmenden Alter. 
Sehwankungen der Gefäßwände ingleicher Höhe.

Ich erwähnte vorhin, daß ich als Einheit der Wanddicke den Mittelwert aus dickster und dünnster Stelle der Aorta am Zwerchfell gewählt habe. Dementsprechend mußte ich natürlich auch bei der Aufstellung der relativen Dickenverhältnisse das Mittel aus höchstem und niederstem Wert berechnen. Es fiel mir dabei an der Aorta eine gewisse Gesetzmäßigkeit der Dickendifferenzen in gleichen Höhen auf, derart, daß im aufsteigenden Teile die konkave Seite dicker ist als die konvexe, im absteigenden die ventrale dicker ist als die dorsale; an der Teilungsstelle konnte ich dagegen kein konstantes Verhältnis finden. Diese Verhältnisse rühren vielleicht her von der Art der Verästelung der Aorta und davon, daß die freiliegenden und somit ,frei pulsierenden" Strecken sich mächtiger entwickeln. Diese nicht durch ihre Umgebung gestützten Stellen (ohne Unterlage und Haltepunkte) sind diejenigen, deren elastische Funktion am meisten in Anspruch genommen wird.

Verhaltender Gefäßebei Hypoplasie und Atrophiedes Herzens.

Zur systematischen Untersuchung des Verhältnisses zwischen Herzhypoplasie und -atrophie einerseits, Mächtigkeit der Arterienentwicklung andererseits habe ich sämtliche Fälle mit niederem Herzgewicht (d. h. für erwachsene Männer unter $250 \mathrm{~g}$, für erwachsene Frauen unter $210 \mathrm{~g}$ ) zusammengestellt und nach Hypoplasie und Atrophie getrennt untersucht. Die Fälle mit hypoplastischen Herzen ergeben kein übereinstimmendes Bild. Wohl finden wir in den meisten Fällen zu geringe Maße an den Arterien; allein die niedrigen Zahlen beschränken sich häufig nur auf den Umfang oder auf die.Dicke, häufig auch nur auf eine bestimmte Höhe der Aorta, mit Vorliebe auf den über den Klappen befindlichen Teil; es besteht hier offenbar eine gewisse Abhängigkeit von der Kleinheit des Herzens und des Aortenostiums. Gleichzeitig zu eng und zu dünn erwies sich die Aorta nur in 4 von 16 Fällen (S.-Nr. 997/08, 18 jähriger Mann; S.-Nr. 154/09, 18 jähriger Mann; S.-Nr. 203/09, 28 jähriges Weib; S.-Nr. 1163/08, 36 jähriges Weib). Wir greifen folgende zwei Fälle heraus:

S.-Nr. 154/09. 18 jähriger Mann. Körperlänge $163 \mathrm{~cm}$, Körpergewicht $34,45 \mathrm{~kg}$, Herzgewicht $200 \mathrm{~g}$. Anatomische Diagnose: chronische indurierende Lungentuberkulose.

\begin{tabular}{|c|c|c|c|c|}
\hline \multicolumn{5}{|c|}{ Gefäßmessungen: } \\
\hline & \multicolumn{2}{|c|}{ Umfang } & \multicolumn{2}{|c|}{ Dicke } \\
\hline Aorta über Klappe & 5,0 & $(5,2)$ & $\left\{\begin{array}{l}1,32 \\
1,48\end{array}\right.$ & $\begin{array}{l}(1,49) \\
(1,80)\end{array}$ \\
\hline Aorta hinter Bogen & 3,8 & $(4,3)$ & $\left\{\begin{array}{l}1,06 \\
1,18\end{array}\right.$ & $\begin{array}{l}(1,14) \\
(1,35)\end{array}$ \\
\hline Aorta am Zwerchfell & 3,6 & $(4,0)$ & $\left\{\begin{array}{l}1,06 \\
1,20\end{array}\right.$ & $\begin{array}{l}(1,15) \\
(1,32)\end{array}$ \\
\hline Aorta an Teilungsstelle & 2,7 & $(2 ; 8)$ & $\left\{\begin{array}{l}0,94 \\
1,16\end{array}\right.$ & $\begin{array}{l}(1,01) \\
(1,27)\end{array}$ \\
\hline
\end{tabular}

Virchows Archiv f, pathol, Anat. Bd. 201. Hft. 1. 
Auch außerdem beobachtet man bei jüngeren Leuten, die mit Lungentuberkulose behaftet sind, bei kleinem Herzen häufig dünnwandige Aorta.

S.-Nr. 203/09. Weib, 28 Jahre. Körperlänge 1,54 m, Körpergewicht $41 \mathrm{~kg}$, Herzgewicht 190 g. Anatomische Diagnose: Sepsis nach Operation von Graviditas extrauterina.

Gefäßmessungen:

\begin{tabular}{|c|c|c|c|c|}
\hline \multirow[b]{2}{*}{ Aorta über Klappe } & \multicolumn{2}{|c|}{ Umfang } & \multicolumn{2}{|c|}{ Dicke } \\
\hline & 5,3 & $(5,5)\{$ & $\left\{\begin{array}{l}1,28 \\
1,56\end{array}\right.$ & $\begin{array}{l}(1,42) \\
(1,65)\end{array}$ \\
\hline Aorta hinter Bogen & 4,1 & $(4,4)$ & $\left\{\begin{array}{l}0,84 \\
1,10\end{array}\right.$ & $\begin{array}{l}(1,18) \\
(1,33)\end{array}$ \\
\hline Aorta am Zwerchfell & 3,8 & $(4,1)$ & $\left\{\begin{array}{l}0,80 \\
1,08\end{array}\right.$ & $\begin{array}{l}(1,07) \\
(1,27)\end{array}$ \\
\hline Aorta an Teilung & 3,0 & $(3,0)$ & $\left\{\begin{array}{l}0,80 \\
1,20\end{array}\right.$ & $\begin{array}{l}(1,00) \\
(1,18)\end{array}$ \\
\hline
\end{tabular}

Sehr konstante Befunde ergab die Messung des Pulmonalumfanges bei Herzhypoplasie. Nur in einem einzigen Falle (S.-Nr. 12/09, 25 jähriges Weib) war die Pulmonalis zu weit, in zwei Fällen (S.-Nr. 994/08, 18 jähriges Weib und S.-Nr. 203/09, 28 jähriges Weib) etwa gehörig weit. In allen anderen Fällen blieb ihre Lichtung zum Teil recht beträchtlich (im Fall S.-Nr. 139/09, 32 jähriges Weib und S.-Nr. 1163/08, 36 jähriges Weib, um $1 \mathrm{~cm}$ ) hinter dem Durchschnitt zurück. Auch die Wanddicke ist ziemlich regelmäßig zu gering. Für den einzigen Fall, wo sie zu hohe Dickenwerte aufweist (S.-Nr. 97/09, 23 jähriges Weib) mag die Erklärung vielleicht in der Todesursache (chronische indurierende und ulzerierende Lungentuberkulose mit relativer rechtsseitiger Herzhypertrophie) zu suchen sein, ein Punkt, auf den ich schon aufmerksam machte. In drei weiteren Fällen (S.-Nr. 994/09, 18 jähriges Weib; S.-Nr. 12/09, 25 jähriges Weib; S.-Nr. 203/09, 28 jähriges Weib; S.-Nr. 1163/08, 36 jähriges Weib) hält sich die Wanddicke in den Grenzen des Normalen, d. h. des Durchschnittes.

Ein ganz anderes Bild entrollt der zweite Teil jener von mir angelegten Tabelle. Selbst bei hochgradiger erworbener (seniler) Herzatrophie erscheinen die Gefäße ziemlich unbeeinflußt; sie haben normale Wanddicke. Offenbar wird eine einmal dem Alter entsprechend entwickelte Aorta nicht mehr atrophisch. Es sind die Fälle, wo gleich die einfache Betrachtung bei der Obduktion das Mißverhältnis zwischen dem Kaliber des Arteriensystems, besonders der Aorta, und den geringen Herzdimensionen auffällig ergibt. Vereinzelte Fälle, bei denen sich die Aorta in ihrem ganzen Verlauf oder nur über der Klappe als zu eng erwies, müssen als Ausnahmen gelten, die die Regel bestätigen. Anders bei der Arteria pulmonalis. Hier sehen wir ausnahmslose, zum Teil recht beträchtlich (bis 1,3 cm) hinter dem Durchschnitt bleibende Umfangsmaße. Die Wanddicke ist im allgemeinen etwas zu gering, teilweise jedoch auch gehörig und sogar zu groß. Eine Erklärung für dieses auffällige Verhalten (Inaktivitätsatrophie?) der Pulmonalis, welches sich ohne Ausnahme in 8 darauf untersuchten Fällen ergab, können wir nicht geben.

Den Zusammenhang zwischen chronischen Lungenkrankheiten und Verstärkung der Pulmonalwand veranschaulichen die Fälle (S. N. 22./09, M. 27 J.; S. N. $1087 / 08$ M. 50 J.; S. N.; S. N. 1091/08 M. 71 J.) 
S.-Nr. 22/09. Mann, 27 Jahre. Körperlänge $162 \mathrm{~cm}$, Körpergewicht $31 \mathrm{~kg}$, Herz $182 \mathrm{~g}$. 'Anatomische Diagnose: Chronische und akute ulzerierende und peribronchiale Lungentuberkulose. Hochgradige Tuberkulose der Harnblase. Braune Atrophie des Herzens.

$\begin{array}{cc}\text { Umfang } & \text { Dicke } \\ 6,0 \quad(6,6) & \begin{cases}1,20 & (1,03) \\ 1,44 & (1,30)\end{cases} \end{array}$

S.-Nr. 1087/08. Mann, 50 J. Körperlänge $158 \mathrm{~cm}$, Körpergewicht $39 \mathrm{~kg}$, Herzgewicht 250 g. Anatomische Diagnose: Chronische indurierende und ulzerierende Lungentuberkulose. Beginnende braune Degeneration des Herzens. Chronische indurierende Nephritis.

Umfang

$7,5 \quad(7,8)$
Dicke

$$
\{1,48 \quad(1,18)
$$$$
\{1,70(1,44)
$$

H y p oplasiedes Gefäßs ystems.

Hypoplastische - zu enge und gleichzeitig zu dünnwandige - Gefäße sah ich nicht selten bei gleichzeitiger Herzhypoplasie. Dagegen scheinen sie mir bei normalem oder etwas vergrößertem Herzen, also in Form der „Enge der Aorta“" im Virch o w schen Sinne sehr selten zu sein. Einen reinen Fall konnte ich wenigstens nicht finden. Vier Fälle aus meinem Material kommen insofern in Betracht, als in zwei Fällen (S.-Nr. 5/09, 28 jähriges Weib; S.-Nr. 215/09, 37 jähriges Weib) die Aorta wohl eng und dünn war, aber nur über der Klappe; in den beiden andern Fällen (S.-Nr. 94/09, 34 jähriges Weib; S.-Nr. 178/09, 26 jähriger Mann) hingegen war die Aorta in ihrem ganzen Verlauf wohl dünnwandig, wies aber normalen Umfang auf.

1. S.-Nr. 215/09. 37 jühriges Weib. Körperlänge $142 \mathrm{~cm}$, Körpergewicht $34 \mathrm{~kg}$, Herzgewicht $315 \mathrm{~g}$. Anatomische Diagnose: Sepsis, ausgehend von sehr ausgedehnter kavernöser Tuberkulose beider Lungen.

\begin{tabular}{|c|c|c|c|c|}
\hline \multirow[b]{2}{*}{ Aorta über Klappe } & \multicolumn{2}{|c|}{$\begin{array}{l}\text { ungen: } \\
\text { Umfang }\end{array}$} & \multicolumn{2}{|c|}{ Dicke } \\
\hline & 5,2 & $(6,0)$ & $\left\{\begin{array}{l}1,30 \\
1,50\end{array}\right.$ & $\begin{array}{l}(1,59) \\
(1,86)\end{array}$ \\
\hline Aorta hinter Bogen & 4,3 & $(4,6)$ & $\left\{\begin{array}{l}1,12 \\
1,42\end{array}\right.$ & $\begin{array}{l}(1,31) \\
(1,41)\end{array}$ \\
\hline Aorta am Zwerchfell & 4,0 & $(4,2)$ & $\left\{\begin{array}{l}1,14 \\
1,28\end{array}\right.$ & $\begin{array}{l}(1,25) \\
(1,40)\end{array}$ \\
\hline Aorta an Teilungsstelle & 3,2 & $(3,5)$ & $\left\{\begin{array}{l}1,00 \\
1,20\end{array}\right.$ & $\begin{array}{l}(1,03) \\
(1,28)\end{array}$ \\
\hline
\end{tabular}

2. S.-Nr. 178/09. 26 jähriger Mann. Körperlänge $1,71 \mathrm{~m}$, Körpergewicht $47 \mathrm{~kg}$, Herzgewicht 400. g. Anatomische Diagnose: Tuberkulöser Pyopneumothorax der rechten Seite mit teilweiser schwartiger Obliteration der rechten Pleurahöhle; große, alte Kaverne der rechten Lungenspitze; rezidivierende knotige peribronchiale Tuberkulose der ganzen rechten Lunge.

\section{Gefäßmessungen:}

\begin{tabular}{|c|c|c|c|c|}
\hline & \multicolumn{2}{|c|}{ Umfang } & \multicolumn{2}{|c|}{ Dicke. } \\
\hline Aorta über Klappe & 6,2 & $(5,9)$ & $\left\{\begin{array}{l}1,38 \\
1,56\end{array}\right.$ & $\begin{array}{l}(1,58) \\
(1,82)\end{array}$ \\
\hline Aorta hinter Bogen & 4,5 & $(4,7)$ & $\left\{\begin{array}{l}0,96 \\
1,30\end{array}\right.$ & $\begin{array}{l}(1,23) \\
(1,45)\end{array}$ \\
\hline Aorta am Zwerchfell & 4,3 & $(4,3)$ & $\left\{\begin{array}{l}0,94 \\
1,16\end{array}\right.$ & $\begin{array}{l}(1,21) \\
(1,30)\end{array}$ \\
\hline orta an Teil & 3,1 & $(3,3)$ & $\left\{\begin{array}{l}0,98 \\
1,18\end{array}\right.$ & $\begin{array}{l}(1,09) \\
(1,26)\end{array}$ \\
\hline
\end{tabular}




\section{VerhaltenderGefäßebei Herzhypertrophie ohne Arteriosklerose.}

Im Gegensatz zu den fast ausnahmslos angetroffenen, wenn auch in Art und Größe differierenden Gefäßabweichungen bei Herzhypoplasie und -atrophie bleibengesunde, d. h. von Arteriosklerose und Lues versehonte Gefäbe-die Pulmonalis ausgenommen - von der Herzhypertrophie ziemlich unbeeinfluBt. Eine Tabelle (nicht mit veröffentlicht), in der ich alle Fälle mit Herzgewicht über $400 \mathrm{~g}$ - abgesehen von den durch Klappenfehlern, Syphilis und Schrumpfniere bedingten Herzhypertrophien - aufgeführt habe, beweist diese Behauptung.

Die gesunde Aorta behält ihre dem Alter und Geschlecht entsprechenden Maße fast durchgehends bei, gleichgültig, welche Vergrößerungen das Herz erleidet. Dies ist besonders deshalb bemerkenswert, weil die sogenannten idiopathischen Herzhypertrophien oft mit einer nicht anzuzweifelnden Plethora verbunden sind, und diese Plethora nach unseren Beobachtungen also nicht imstande wäre, das arterielle System in seiner Weite und Wandbeschaffenheit zu ändern. Namentlich im jugendlichen Alter, wo offenbar die große Elastizität der Gefäßwand der vermehrten Inanspruchnahme von seiten des hypertrophischen Herzens das Gleichgewicht zu halten scheint, zeigt sich dies sehr deutlich. Ja, hier wird am Sektionstisch sogar recht oft in uns der Gedanke einer zu engen Aorta wachgerufen; allerdings in den meisten Fällen wohl eine Täuschung, bedingt durch die Größe des Herzens. Jedermann kennt diese Fälle, in denen man immer wieder geneigt ist, eine Hypoplasie des Aortensystems zu diagnostizieren und in denen uns bloß die genaue Kenntnis von den allerdings noch zu wenig bekannten Normalzahlen davon abhalten kann. Auch die Wanddicke hält sich bei unversehrten Gefäßen in normalen Grenzen, bleibt manchmal selbst hinter dem Durchschnitt zurück. Es sei mir gestattet, zur Veranschaulichung der Unabhängigkeit des Gefäßsystems von Herzvergrößerungen einige interessante Fälle genau zu beschreiben.

1. S.-Nr. 221/09. Männliches Kind, 11/2 Jahre alt. Anatomische Diagnose: Schwielige Myokarditis des linken Herzens; sehr starke Dilatation und Hypertrophie des linken Herzens mit hochgradiger Endokardverdiekung; Hypertrophie des linken Vorhofes. Chronisehe Lungenstauung (rote Kondensation und chronisches Ödem). Starke Hypertrophie und geringe Dilatation des rechten Herzens. Subakute konfluierende, paravertebrale Pneumonie der linken Lunge; chronische und akute Bronehitis. Zystöse Erweichung des rechten Centrum semiovale und von Rindenteilen. Chronische Enzephalitis und enzephalitische Atrophie anderer Teile der rechten Hemisphäre. Hydrocephalus externus. Indurierte Stauungsmilz; chronische Stauung und Ödem von Leber und Nieren: Das Herzgewicht beträgt $130 \mathrm{~g}$ statt $45 \mathrm{~g}$.

\begin{tabular}{|c|c|c|c|c|}
\hline \multirow[b]{2}{*}{ Aorta über Klappe } & \multicolumn{2}{|c|}{$\begin{array}{l}\text { ungen: } \\
\text { Umfang }\end{array}$} & \multicolumn{2}{|c|}{ Dicke } \\
\hline & 3,0 & $(3,4)$ & $\left\{\begin{array}{l}0,84 \\
1,04\end{array}\right.$ & $\begin{array}{l}(1,09) \\
(1,26)\end{array}$ \\
\hline Aorta hinter Bogen & 2.2 & $(2,3)$ & $\left\{\begin{array}{l}0,58 \\
0,72\end{array}\right.$ & $\begin{array}{l}(0,77) \\
(0,89)\end{array}$ \\
\hline
\end{tabular}


Es ist hier also die Aorta trotz der starken Herzhypertrophie enger und dünner, als es dem Alter entspricht (das Kind befand sich im übrigen in normalem Ernährungszustande). Umgekehrt wurde aber in solchen Fällen die Herzhypertrophie auch als Ausgleichserscheinung für die hypoplastische Aorta aufgefaßt.

2. S.-Nr. 984/08. Gesunder, kräftiger Mann von 45 Jahren. Tod durch Kohlensäurevergiftung. Körperlänge $1,85 \mathrm{~m}$, Körpergewicht $79 \mathrm{~kg}$, Herzgewicht $480 \mathrm{~g}$.

Ungeachtet dieser kräftigen Allgẹmeinentwicklung sind die Aortenwände sehr dünn:

\begin{tabular}{|c|c|c|}
\hline \multicolumn{3}{|c|}{ Gefäßmessungen: } \\
\hline & Umfang & Dicke \\
\hline Aorta über Klappe & $7,0 \quad(7,3)$ & $\begin{cases}1,09 & (1,59) \\
1,25 & \\
1,48 & (1,83)\end{cases}$ \\
\hline Aorta hinter Bogen & $5,5 \quad(5,4)$ & $\begin{cases}1,28 & (1,56) \\
1,30 & (1,69)\end{cases}$ \\
\hline
\end{tabular}

Meiner vorhin aufgestellten und durch diese beiden Beispiele belegten Behauptung, daß Herzhypertrophie auf nicht pathologisch veränderte Gefäße keinen oder doch nur ganz geringen Einfluß habe, scheinen die hohen Zahlen des Falles S.-Nr. 1118/08 (40 jähriges Weib) zu widersprechen. Allein die Erklärung hierfür liegt in einer andern, recht interessanten Tatsache. Ich habe nämlich gefunden, daß Frauen mit allgemeiner Fettsucht zu weite und besonders zu dickwandige Aorten besitzen.

S.-Nr. 1118/08. 40 jährige Frau. Körperlänge 1,49 m, Körpergewicht 102 kg, Herzgewicht 455 g. Anatomische Diagnose: Adipositas cordis. Hypertrophie und Dilatation des Herzens. Allgemeine hochgradige Adipositas.

\begin{tabular}{|c|c|c|c|c|}
\hline \multicolumn{5}{|c|}{ Gefäßmessungen: } \\
\hline Aorta über Klappe & 6,5 & $(6,0)$ & $\left\{\begin{array}{l}1,86 \\
1,94\end{array}\right.$ & $\begin{array}{l}(1,59) \\
(1,86)\end{array}$ \\
\hline Aorta hinter Bogen & 4,8 & $(4,6)$ & $\left\{\begin{array}{l}1,40 \\
1,50\end{array}\right.$ & $\begin{array}{l}(1,31) \\
(1,41)\end{array}$ \\
\hline Aorta am Zwerchfell & 4,2 & $(4,2)$ & $\left\{\begin{array}{l}1,54 \\
1,60\end{array}\right.$ & $\begin{array}{l}(1,25) \\
(1,41)\end{array}$ \\
\hline
\end{tabular}

Ein ähnlicher, noch ausgeprägterer Fall:

S.-Nr. 127/09. Weib, 58 Jahre. Körperlänge 1,55 m, Körpergewicht $130 \mathrm{~kg}$, Herzgewicht 600 g. Anatomische Diagnose: hochgradige allgemeine Fettsucht. Konzentrische Herzhypertrophie und starke Adipositas cordis mit geringer Fettdurchwachsung. Zyanotische Induration der Organe. Stauungsblutung von Magen, Darm und Pankreas. Polyposis des Magens.

\begin{tabular}{|c|c|c|c|c|}
\hline \multicolumn{3}{|c|}{ Gefäßmessungen: } & \multicolumn{2}{|c|}{ Dicke } \\
\hline Aorta über Klappe & 6,8 & $(7,3)$ & $\left\{\begin{array}{l}1,86 \\
2,06 \\
2,36\end{array}\right.$ & $\begin{array}{l}(1,77) \\
(2,00)\end{array}$ \\
\hline Aorta hinter Bogen & 6,0 & $(5,4)$ & $\left\{\begin{array}{l}1,90 \\
2,30\end{array}\right.$ & $\begin{array}{l}(1,53) \\
(1,66)\end{array}$ \\
\hline orta am $\mathrm{Zw}$ & 5,7 & $(5,2)$ & $\left\{\begin{array}{l}1,74 \\
1,90\end{array}\right.$ & $\begin{array}{l}(1,42) \\
(1,56)\end{array}$ \\
\hline
\end{tabular}


Ein viel empfindlicheres Verhalten bei Herzhypertrophie zeigt wieder die Arteria pulmonalis; namentlich bei rechtsseitiger Herzhypertrophie erweitert sie sich unter gleichzeitiger Dickenzunahme recht regelmäßig. Utberhaupt scheint, wie schon früher angedeutet, ihre Wanddicke, die selbst die Maße der Aorta über der Klappe erreichen kann, nicht so sehr vom Alter, als vielmehr von der Anstrengung des kleinen Kreislaufes und Herzhypertrophie abhängig zu sein. Die im Alter ja wohl höheren Durchschnittsdickenwerte resultieren eben aus der häufigen Herzhypertrophie rechterseits wegen Emphysem oder anderer chronischer Lungenkrankheiten.

\section{Verhaltender GefäBebei Herzhypertrophiemit Arteriosklerose.}

Außer der feinen Anpassungsfähigkeit der Pulmonalis konnte ich, wie gezeigt, bei Herzhypertrophie ohne Arteriosklerose nur recht geringgradige, zum Teil überhaupt keine Wirkung auf die großen Gefäße erkennen. Anders bei Herzhypertrophie mit Arteriosklerose. Wohl sind auch hier die Veränderungen des Umfanges und der Wanddicke nicht gesetzmäßig - aber Veränderungen sind immer da. Bald findet sich geringe, bald hochgradige, bald auf die aufsteigende, bald auf eine Partie der absteigenden Aorta beschränkte, bald über die ganze Aorta sich erstreckende Erweiterung; die Wanddicke ist bald verringert, bald auf wechselnde Bezirke oder diffus vermehrt, in seltenen Fällen normal.

Die genaue Beschreibung einiger Fälle möge dies beleuchten:

S.-Nr. 228/09. Mann, 50 Jahre. Körperlänge 1,62 m, Körpergewicht $63 \mathrm{~kg}$, Herzgewicht 440 g. Anatomische Diagnose: Schlaffe, kruppöse Pneumonie des rechten Oberlappens. Sekundäre, serofibrinöse Pleuritis, Hydrothorax. Anämie sämtlicher Organe. Idiopathische Hypertrophie des Herzens. In der ganzen Aorta zerstreut viele weiße Flecken und zum Teil starke Verkalkungen.

\begin{tabular}{cccc}
\multicolumn{3}{c}{ Gefäßmessungen: } & \\
& Umfang & \multicolumn{2}{c}{ Dicke } \\
Aorta über der Klappe & 9,0 & $(7,3)$ & $\left\{\begin{array}{cc}1,36 & (1,59) \\
1,60 & (1,83)\end{array}\right.$ \\
Aorta am Zwerchfell & $7,5 \quad(5,3)$ & $\begin{cases}1,06 & (1,39) \\
1,38 & (1,60)\end{cases}$ \\
& verkalkte & Stellen \\
& bis & $1,60$.
\end{tabular}

Die Aorta ist also dünnwandig und sehr stark erweitert; wohl eine Folge der Elastizitätsabnahme.

Doch auch über die Norm dickwandige Aorten kommen vor:

S.-Nr. 276/09. Mann, 50 Jahre. Körperlänge $1,72 \mathrm{~m}$, Körpergewicht $75 \mathrm{~kg}$, Herzgewicht $1000 \mathrm{~g}($ !). Anatomische Diagnose: Exzessive Hypertrophie, mäßige Dilatation des ganzen Herzens. Chronische Stauung und Emphysem der Lungen; chronische Bronchitis. Schleichende Perihepatitis und Perisplenitis. Indurierte Stauungsorgane. Hochgradige Atrophie der linken Niere mit fast vollkommenem endarteriitischen Verschluß ihrer Arterie. MäBige vikariierende Hypertrophie und chronische Nephritis der rechten Niere. Stauungskatarrh und Hämochromatose von Magen und Darm. Allgemeine hochgradige Arteriosklerose. 


\begin{tabular}{lccc}
\multicolumn{4}{c}{ Gefäßmessungen: } \\
& Umfang & Dicke \\
Aorta über der Klappe & 8,0 & $(7,3)$ & $\begin{cases}2,20 & (1,59) \\
2,40 & (1,83)\end{cases}$ \\
Aorta hinter Bogen & 6,0 & $(5,4)$ & $\begin{cases}1,80 & (1,56) \\
2,00 & (1,69)\end{cases}$ \\
& & Beetartig verdickte \\
& Stellen bis $2,70$.
\end{tabular}

Das sind die höchsten Zahlen, die ich überhaupt zu verzeichnen habe. Die mikroskopische Messung einer Stelle der Aorta über der Klappe ergab:

$$
\begin{array}{lcc}
\text { Intima } & \mathbf{0 , 1 8 5}-0,240 & (0,111-0,123) \\
\text { Media } & 1,850 & (1,723-1,757)
\end{array}
$$

Wie in diesem Falle, so hat ganz allgemein bei Herzhypertrophie - auch ohne Arteriosklerose - die Verdickung der Aorta ihren Grund häufig vorzüglich in verdickter Intima. Schon bei Kindern kann man das beobachten.

7. XII. 09. 8 jähriges Kind. Herzgewicht 165 g. Anatomische Diagnose: Kyphoskoliose. Chronische Bronehitis. Sehr starke Hypertrophie und Dilatation des rechten Herzens.

Aus dem Protokoll: In den feinen Lungenarterien sind vereinzelte gelbe Flecken; der Pulmonalstamm ist sehr dickwandig, aber ohne Flecken. Mikroskopische Messungen:

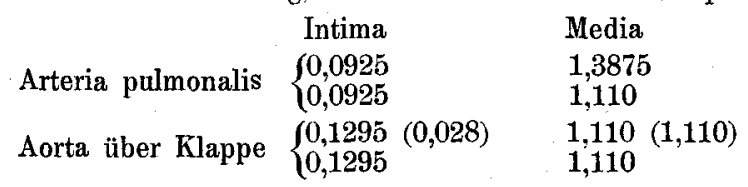

Als Vergleichszahlen konnte ich hier nur die Werte eines einzigen Falles angeben. Es war dies ein neunjähriges Mädchen, bei dem die Gefäße normal zu sein schienen.

Bei solchen Verdickungen zeigt das mikroskopische Bild bei älteren Individuen meist unter der Intima geringe fettige Degeneration, im jugendlichen Alter fehlt eine solche meist ganz.

Schließlich möchte ich noch erwähnen, daß ich nicht gar selten bei Herzhypertrophien (und auch bei andern Herzkrankheiten) makroskopisch normal dicke Gefäßwände mikroskopisch untersucht und zu meiner Uberraschung eine zu dünne Media gefunden habe, kompensiert durch verdickte Adventitia. Um Mißverständnissen vorzubeugen, möehte ich bemerken, daß ich zur mikroskopischen Messung stets die Adventitia mittels Schere abpräparierte. Für gewöhnlich fanden sich dann im mikroskopischen Bilde nur mehr ganz geringe Reste oder gar nichts von der Adventitia vor. In diesem Falle zeigte sich jedoch die nicht abpräparierte Adventitia in der unten aufgeführten Dicke.

Zum Beispiel S.-Nr. 1172/08. Mann, 41 Jahre. Anatomische Diagnose: Starke Hypertrophie und Dilatation des Herzens; stenosierende fibröse Endokarditis der Mitralis; Schrumpfung der Aortenklappen.

Makroskopisch

$\begin{array}{cc}\text { Umfang } & \text { Dicke } \\ & 1,60(1,59) \\ 8,3(7,3) & 2,24(1,83)\end{array}$

Messung der Aorta über Klappe

Mikroskopisch

\begin{tabular}{ccccc} 
Intima & \multicolumn{2}{c}{ Media } & Adventitia & \\
0,074 & $(0,073)$ & $1,295(1,541)$ & 0,465 & (für gewöhnlich \\
$0,0925(0,154)$ & $1,3875(1,603)$ & 0,465 & gar nichts)
\end{tabular}


Das in den meisten Fällen relativ niedrige Gewicht der Aorta bei Herzhypertrophie habe ich schon früher betont.

Verhalten der Gefäße bei allgemeiner Arteriosklerose.

Die interessanten Gefäßbefunde bei Herzhypertrophie mit gleichzeitiger Arteriosklerose veranlaßten mich, auch an arteriosklerotischen Gefäßen ohne begleitende Herzhypertrophie Messungen vorzunehmen. Eine genaue Durchsicht meiner Tabellen lehrt, daß sich hierbei die Aorta durchschnittlich erweitert, besonders deutlich in präsenilen Fällen und allerdings, wie bereits erörtert, besonders bei gleichzeitig vorhandener Herzhypertrophie. Im Gegensatz dazu fand ich bei atrophischen Herzen manchmal eine gewisse Verengerung von sklerotischen Gefäßen.

Die Wanddicke verhält sich recht unregelmäßig; bald ist sie normal, bald vermehrt, in der Mehrzahl der Fälle vielleicht doch vermindert. Wenn ich daher die Aorta bei allgemeiner Arteriosklerose im großen und ganzen als zu weit und zu dünn bezeichne, so ist das cum grano salis zu nehmen. Ich möchte wenigstens einen dafür typischen Fall erwähnen.:

S.-Nr. 244/09. Mann, 44 J. Körperlänge 1,65 m, Körpergewicht 69 kg, Herzgewicht $370 \mathrm{~g}$. Anatomische Diagnose: Dilatation der sämtlichen Herzabschnitte, namentlich des rechten Ventrikels, mit mäßiger Hypertrophie des letzteren. Arteriosklerose der absteigenden Aorta.

\begin{tabular}{|c|c|c|c|c|}
\hline \multirow[b]{3}{*}{ Aorta über Klappe } & \multirow{2}{*}{\multicolumn{2}{|c|}{ Umfang }} & \multirow{2}{*}{\multicolumn{2}{|c|}{ Dicke }} \\
\hline & & & & \\
\hline & 8,0 & $(7,3)$ & $\left\{\begin{array}{l}0,90 \\
1,34\end{array}\right.$ & $\begin{array}{l}(1,59) \\
(1,83)\end{array}$ \\
\hline Aorta hinter Bogen & 5,6 & $(\mathbf{5}, \mathbf{4})$ & $\left\{\begin{array}{l}1,20 \\
1,40\end{array}\right.$ & $\begin{array}{l}(1,56) \\
(1,69)\end{array}$ \\
\hline Aorta am Zwerchfell & & & $\left\{\begin{array}{l}1,12 \\
1,32\end{array}\right.$ & $\begin{array}{l}(1,39) \\
(1,60)\end{array}$ \\
\hline Aorta an Teilungsstelle & 4,7 & $(4,1)$ & $\left\{\begin{array}{l}0,90 \\
1,10\end{array}\right.$ & $\begin{array}{l}(1,18) \\
(1,33)\end{array}$ \\
\hline Arteria iliaca com. & 3,5 & $(2,8)$ & $\left\{\begin{array}{l}0,90 \\
1,08\end{array}\right.$ & $\begin{array}{l}(0,98) \\
(1,25)\end{array}$ \\
\hline Mikroskopische & $\begin{array}{r}\text { Messunge } \\
\text { Intima }\end{array}$ & n der & $\begin{array}{l}\text { Aorta } \\
\text { Med }\end{array}$ & \\
\hline über Klappe & 0,0555 & & 0,74 & \\
\hline an anderer Stelle & 0,0925 & & 0,92 & \\
\hline
\end{tabular}

In einem Falle von hochgradiger Atheromatose begegnete ich einer eigenartigen Aortaschichtung.

S. Nr. 114/09. Weib, 26 Jahre. Anatomische Diagnose: Sepsis ansgehend von einem Abszeß des Rückens. Trübe Sehwellung und Fettdurehwachsung des Herzens. Hochgradige Atheromatose der Aorta. Frische Perikarditis. Adhäsive und exsudative Pleuritis beiderseits. Starkes Ödem beider Lungen. Septischer Milztumor. Trübe Schwellung und Stauung der Leber; parenchymatöse Degeneration und Stauung beider Nieren. Die Frau machte einen früh gealterten Eindruck. Die makroskopischen und mikroskopischen Messungen der Gefäßwanddicke ergaben: 


\begin{tabular}{|c|c|c|c|c|c|}
\hline & \multicolumn{2}{|c|}{ Makroskopisch } & \multicolumn{3}{|c|}{ Mikroskopisch } \\
\hline & Umfang & Dicke & Intima & Media & Adventitia \\
\hline Aorta über Klappe & 5,5 & $\left\{\begin{array}{l}1,48 \\
1,88\end{array}\right.$ & $\begin{array}{l}0,637 \\
0,555\end{array}$ & $\begin{array}{l}1,480 \\
1,295\end{array}$ & ca. 0,370 \\
\hline Aorta hinter Bogen & 4,2 & $\left\{\begin{array}{l}1,18 \\
1,50\end{array}\right.$ & $\begin{array}{l}0,740 \\
1,0175\end{array}$ & $\begin{array}{l}0,925 \\
0,925\end{array}$ & stark \\
\hline Aorta am Zwerchfell & 4,4 & $\left\{\begin{array}{l}1,64 \\
1,94\end{array}\right.$ & $\begin{array}{l}1,295 \\
1,3875\end{array}$ & $\begin{array}{l}0,6475 \\
0,4625\end{array}$ & $\begin{array}{l}0,370 \\
0,555\end{array}$ \\
\hline Aorta an Teilungsstelle & le 3,2 & 1,20 & $\left\{\begin{array}{l}1,0175 \\
0,925 \\
1,665\end{array}\right.$ & $\begin{array}{l}0,6475 \\
0,6475 \\
0,4625\end{array}$ & $\begin{array}{c}0,555 \\
0,925\end{array}$ \\
\hline Arteria il. com. & 2,0 & $\left\{\begin{array}{l}0,84 \\
1,14\end{array}\right.$ & 0,028 & 0,555 & 0,370 \\
\hline Carotis com. & 1,5 & $\left\{\begin{array}{l}0,84 \\
1,26\end{array}\right.$ & $\begin{array}{l}0,6475 \\
0,028\end{array}$ & $\begin{array}{l}0,370 \\
0,4625\end{array}$ & $\begin{array}{l}0,555 \\
0,925\end{array}$ \\
\hline
\end{tabular}

Die Intima ist also stark - teils bis $1 \mathrm{~mm}$ - verdickt; fettige Degeneration fand sich nur stellenweise, und da in geringem Grade. Zwischen Intima und Media fand sich an einigen Stellen geringgradige Gefäßwucherung und Zellinfiltration, an andern Stellen ausgebreitete Blutungen.

Die Media ist staunenswert dünn - in der Aorta am Zwerchfell nur 0,4625 bis $0,6475 \mathrm{~mm}$ - hie und da stark von Bindegewebe durchwachsen. Trotz dieser außerordentlich schwachen Mediaschicht haben die Gefäße normalen Umfang, was offenbar der kompensatorisch verdickten Adventitia und Intima zugute zu rechnen ist. Das Zusammentreffen verdickter und fettig degenerierter Intimaschichten mit dünner Media tritt uns bei Arteriosklerose überhaupt häufig entgegen. Die Adventitia war außerdem in dem beschriebenen Falle stark ödematös.

$$
\text { Verhaltender Gefäßebei Schrumpfniere. }
$$

Der Einfluß der Schrumpfniere auf das Herz ist bekannt, weniger im einzelnen der Einfluß auf die Beschaffenheit der Aorta; eine Komponente derselben ist identisch mit der Beeinflussung der Aorta durch Herzhypertrophie überhaupt. Reine Fälle in unserem Sinne, wenn wir von der Abhängigkeit der Gefäße von dem nephritischen Prozesse sprechen wollten, wären also solche, in denen die Herzhypertrophie fehlte. Wir wollen aber, da für die Aufteilung in Spezialunterfragen unser Material nicht groß genug ist, die Verhältnisse bei Schrumpfniere (im ganzen 13 Fälle) im ganzen betrachten.

Hinsichtlich des Umfanges wechseln auch hier wieder die Befunde regellos; er ist bald ziemlich vergröBert, bald etwas verkleinert, bald sind die Umfangszahlen nur in einem gewissen Bereich der Aorta zu groß oder zu klein. Gesetzmäßigeres Verhalten zeigt die Wanddicke, die im großen ganzen, wenn auch verschieden hochgradig, Zunahme erfährt; sie ist als Hypertrophie aufzufassen, weil, wie der folgende Fall zeigt, diese Wanddickenzunahme auf Verdickung der Media beruht.

S.-Nr. 1135/08. Mann, 58 Jahre. Chronische parenchymatöse Nephritis mit Amyloidose.

\begin{tabular}{|c|c|c|c|c|}
\hline & \multicolumn{2}{|c|}{ Makroskopisch } & \multicolumn{2}{|c|}{ Mikroskopisch } \\
\hline & Umfang & Dicke & Intima & Media \\
\hline orta über der Klappe & 8,0 & $\left\{\begin{array}{l}1,38 \\
2,08\end{array}\right.$ & $\begin{array}{l}0,0925(0,111) \\
0,0925(0.123)\end{array}$ & $\begin{array}{l}1,850(1,723) \\
2,035(1,757)\end{array}$ \\
\hline
\end{tabular}


Dünnwandige Aorta habe ich bei Schrumpfniere nur in vereinzelten Fällen, die durch Aortaklappenfehler kompliziert waren, gesehen (S.-Nr. 1021/08, 52 jähriger Mann; S.-Nr. 1121/08, 65 jähriges Weib).

Die häufig angetroffene, auf den Anfangsteil lokalisierte Intimaverdickung in der Arteria renalis mit kalkigen Auflagerungen gehört, als Teilerscheinung der allgemeinen Arteriosklerose, nicht unmittelbar hierher. Bei einigen Fällen von Schrumpfniere und Amyloidniere fand ich die Media etwas verstärkt, die Intima hierfür ziemlich dünn.

Während die Mediadicke der Arteria renalis gewöhnlich 0,2775 bis $0,555 \mathrm{~mm}$ beträgt, fand ich sie bei einem Falle von starker chronischer parenchymatöser Nephritis (S.-Nr. 1172/08, 41 jähriger Mann) 0,4625 bis 0,8325 mm dick. Andere Beispiele für Mediahypertrophie bei chronischer Nierenentzündung sind:

S.-Nr. 1087/08. Mann, 50 J. Chronische indurierende Nephritis. Media: 0,4625-0,6475 mm.

S.-Nr. 1135/08. Mann, 58 J. Chronische parenchymatöse Nephritis mit Amyloiddegeneration $0,555-0,740 \mathrm{~mm}$.

S.-Nr. 1055/08. Weib, 60 J. Schrumpfniere 0,6475-0,925 mm.

S.-Nr. 1174/08. Weib, 70 J. MäBige arteriosklerotische Schrumpfniere 0,092-0,6475 mm.

In zwei von diesen Fällen (S.-Nr. 1135/08, 58 jähriger Mann, und S.-Nr. 1055/08, 60 jähriges Weib) sowie in einem dritten Falle (S.-Nr. 1010/08, 66 jähriges Weib, genuine Schrumpfniere) fand sich in der Adventitia Muskelwucherung vor.

Verhalten der Gefäßebei Aortenklappenfehlern.

Um die Verhältnisse bei Aortenklappenfehlern studieren zu können, muß man sinngemäß unterscheiden zwischen Aorteninsuffizienz und Aortenstenose. Die beiden Herzfehler sind für unsere Frage begreiflicherweise besonders wichtig, da durch eine Insuffizienz der Aortenklappen einerseits große Schwankungen des Blutdrucks im Gefäßrohr stattfinden, durch eine Stenose der Aortenklappen andererseits die Gefäßwände mehr als physiologisch geschont werden. Bedauerlicherweise steht mir nur ein Fall von Aortenstenose zur Verfügung. Theoretische Erwägungen führen $z u$ der Vermutung, daß bei Insuffizienz ihrer Klappen die Aorta zufolge der größeren Blutmenge, die bewältigt werden muß, dilatieren und hypertrophieren wird, ebenso wie die linke Kammer; während für die Stenose in Betracht kommt, ob sie etwa einen atrophierenden Einfluß auf die Aorta auszuüben imstande ist im Gegensatz zu ihrer Wirkung auf das linke Herz. In der Tat stieß ich bei meinen sieben Fällen von Insuffizienz nur ein einziges Mal (S.-Nr. 235/09, 47 jähriges Weib) auf ein allerdings nur ganz wenig $(1 \mathrm{~mm})$ zu niederes Umfangsmaß der Aorta über der Klappe, während in allen andern Fällen die Aorta an dieser Stelle teilweise sogar sehr bedeutend erweitert war. In dem weiteren Verlaufe sind die Verhältnisse des Aortenumfanges nicht übereinstimmend. Die Wanddicke verhält sich an der ganzen Aorta, auch über der Klappe, wechselnd; sie weist bald zu hohe, bald zu geringe Werte auf. An der absteigenden Aorta ist sie, wenn diese relativ zu eng ist, häufig verdickt. In einem Fall erwies sich 
jedoch die ganze Aorta als erweitert und dünnwandig (S.-Nr. 1121/08, 65 jähriges Weib). Bei dem einen Falle von Aortenstenose ist die ganze Brustaorta zu eng; die verhältnismäßig stärkste Abweichung (7,0 cm gegen 7,7 cm Durchschnitt) zeigt sich auch wieder über der Klappe. Die Wanddicke bleibt über der Klappe beträchtlich hinter der Norm zurück, im weiteren Verlauf nivellieren sich die Dickendifferenzen gegen die Norm. Ich glaube also gefunden zu haben, daß tatsächlich ein enger Zusammenhang zwischen Aorta und Aortenstenose einerseits, Aorteninsuffizienz andererseits besteht; daß dieser Abhängigkeit am meisten (vielleicht auch nur) die Aorta ascendens unterworfen ist, und daß es sich bei dem durch Aorteninsuffizienz verursachten Aortaveränderungen teils um reine Dilatation, teils um Dilatation + Hypertrophie handelt. Eine Frage freilich muß ich offen lassen. Ich erwähnte früher, daß ich auf Grund meiner Gefäßuntersuchungen bei Herzatrophie atrophische Vorgänge an den Gefäßen bestreiten müsse. In dem Falle S.-Nr. 83/09, 74 jähriges Weib, Aortenstenose, betragen die Maße der Aorta $7,0 \mathrm{~cm}$ Umfang, 0,96 bis $1,20 \mathrm{~mm}$ Dicke gegen $7,7 \mathrm{~cm}$ Umfang und 1,62 bis $1,84 \mathrm{~mm}$ Dicke des Durchschnittes; an einer einzigen Stelle war die Aorta über der Klappe 1,42 bis 1,62 mm dick. Was liegt nun hier vor: Hypoplasie oder „InaktivitätsAtrophie"? Sowohl hier als überhaupt überall, wo sich verringerte Wanddicke fand, beruht diese auf Verschmälerung der Media; eine solche, manchmal bis unter $1 \mathrm{~mm}$, konnte ich auch in mehreren Fällen feststellen, wo die Gesamtdicke die Normalzahlen einhielt; die Differenz wurde hier von der zu dicken Adventitia ausgeglichen.

Die Arteria iliaca besitzt, wie bei Herzhypertrophie und Arteriosklerose, häufig auch gerade bei Aorteninsuffizienz, in ihrer Adventitia Wucherung der längslaufenden Muskelfasern.

Von der Arteria renalis sei nur erwähnt, daß sich oft ihre Media verdickt; die Intima ist im Gegensatz dazu ziemlich dünn (S.-Nr. 1172/08, 41 jähriger Mann S.-Nr. 1178/08, 72 jähriges Weib).

Bei Klappenfehlern des linken Herzens zeigt schließlich die Pulmonalis eine durch Stauung im kleinen Kreislauf und rechtsseitige Herzhypertrophie zu erklärende Dickenzunahme, auf die oben schon einmal eingegangen wurde.

Die Literatur, die mein Thema behandelt, ist bekannt und zudem in letzter Zeit des öfteren kritisch gesichtet worden, so daß ich nicht des näheren darauf eingehen möchte. Es seien nur die wichtigsten Ergebnisse neuerer Arbeiten erwähnt.

S e h e e l hat versucht, die Zunahme des Aortenlumens mit dem Alter durch mechanische Wirkung des gesteigerten Blutdrucks zu erklären. Dem möchte ich entgegenhalten, daß nach meinen Erfahrungen die Aortawand, namentlich allerdings bei jüngeren Individuen, über eine recht beträchtliche Widerstandskraft gegen erhöhten Blutdruck verfügt; wir finden oft starke Herzhypertrophie mit 
recht geringer, oft ganz fehlender Erweiterung der Aorta, selbst wenn deren Wand dünn ist. Auch B. Fis cher und $\mathrm{Schmieden} \mathrm{haben} \mathrm{durch} \mathrm{ihre} \mathrm{experi-}$ mentellen Untersuchungen über funktionelle Anpassung der Gefäßwand festgestellt, daß eine dauernde Gefäßerweiterung bei erhöhtem Blutdruck nicht eintritt. $\mathrm{S}$ c h e el kommt in Ubereinstimmung mit andern durch Messungen des Aortenumfanges zum Schluß, daß die aus der Literatur gesammelten Angaben über Fälle von Aortenenge ganz gering von den Mittelzahlen seiner Messungen abweichen, wenn man Alter und Geschlecht berücksichtigt. Wenn ich diesem Satze prinzipiell auch vollkommen beistimme, so halte ich doch die Methode seiner zu diesem Resultate führenden Untersuchungen nicht für einwandsfrei. S c h e el hat allein den Aortenumfang gemessen; für allein richtig in morphologischer Hinsicht halte ich die Messung des Verhältnisses von Umfang zu Wanddicke.

B u r k e sammelte die bisher publizierten Fälle vion enger Aorta und kommt im Verein mit seinen eigenen Beobachtungen zum Schluß, daß Herzhypertrophie (insbesondere links) als Folgeerscheinung einer engen Aorta sich einstellen kann. Man kann, glaube ich, in der Beurteilung des Gefäßkalibers nicht vorsichtig genug sein, um sich vor Täuschungen zu bewahren. Gerade bei hypertrophischen Herzen verfallen wir zu leicht dem Fehler, die nur im Vergleich zum vergrößerten Herzen eng erscheinende, in Wirklichkeit aber ganz normal weite Aorta für zu eng und damit nach $\mathrm{Burke}$ für die Ursache der Herzhypertrophie zu halten ${ }^{1}$ ).

\section{Zusammenfassung meiner Befunde.}

1. Für die anatomische Bearbeitung zahlreicher Probleme aus der Pathologie der Gefäße (z. B. der Frage der Hypoplasie und der Hypertrophie von Arterien) ist es unbedingt notwendig, außer der Lichtungsweite auch die Gefäßwanddicke zu messen.

2. Der Umfang der Aorta nimmt ständig von der Geburt bis zum höchsten Alter zu; er ist bei Männern größer als bei Weibern des gleichen Alters.

3. Die Gefäßwanddicke nimmt von der Geburt bis etwa zum fünften Dezennium regelmäßig zu; verglichen mit den Maßen der Weite ergibt sich, daß bis dahin ein wirkliches Wachstum vorliegt. Alle genannten Veränderungen an den großen arteriellen Gefäßrohren sind bis dahin als physiologische zu bezeichnen. Die Differenz der Gefäßwanddicke ist bei den Geschlechtern in der Jugend deutlich, verwischt sich im späteren Leben mehr und mehr.

4. Die Lichtung der Pulmonalis ist in der Jugend größer, im Alter kleiner als die der Aorta über der Klappe. Die Pulmonalis behält ihre Elastizität offenbar bis in höhere Lebensalter als die Aorta und zeichnet sich auch schon in der Jugend bei Belastung des kleinen Kreislaufes durch eine große Anpassungsfähigkeit ihrer

1) Die Arbeit von Strasburger (Frankfurter Ztschr. f. Path. 1909 Bd. III Heft 2) erschien erst nach AbschluB dieser Arbeit und konnte deshalb nicht mehr berïcksichtigt werden. 
verhältnismäßig dünnen Wand aus. Die Anpassung besteht in einer Vermehrung der Mediaelemente und ist demnach als funktionelle Hypertrophie anzusehen.

5. Die längsverlaufendén Muskelfasern der Adventitia hypertrophieren oft im höheren Alter; dies ist höchst wahrscheinlich eine Ausgleichserscheinung für die Abnahme der Leistungsfähigkeit der übrigen Wand und gegen pathologische Blutdruckschwankungen. In der Adventitia der Renalis kommen Neubildungen von querverlaufenden neben den selteneren längsverlaufenden Muskelfasern vor.

6. Eine isolierte Hypoplasie der großen arteriellen Gefäßstämme ist, wenn sie überhaupt vorkommt, jedenfalls äußerst selten. Sie darf nur behauptet werden, wenn neben zu geringer Lichtungsweite eine an funktionell wichtigen Elementen allzu arme Gefäßwand angetroffen wird.

7. Das Verhalten der Aorta bei Hypoplasie des Herzens wechselt sehr. Gleichzeitige Hypoplasie von Herz und Aorta kommt vor. Die Herzatrophie des Alters hat keinen Rückgang von Aortenweite und -dicke zur Folge. Vielleicht kommt jedoch eine Inaktivitätsatrophie der Gefäße (Aorta) bei Aortenstenose vor.

8. Das Verhalten der großen Gefäße bei idiopathischer Herzhypertrophie hängt zum großen Teil vom Alter des Individuums ab. In jüngeren Jahren erweisen sie sich in ihren Wandverhältnissen als hochgradig unabhängig von den Zuständen des Herzens. Im höheren Alter stellen sich in den Anfangsteilen der Aorta, seltener in der ganzen Aorta einfache Erweiterungen ein, die sich wahrscheinlich immer sehr bald mit Arteriosklerose vergesellschaften.

9. Die im Alter und bei Arteriosklerose zu findende, oft recht beträchtliche Erweiterung der Aorta ist auf eine Abnahme der Leistungsfähigkeit der Gefäßwand zurückzuführen, wobei hinsichtlich der Sklerose zu bemerken ist, daß meist nicht festzustellen ist, ob sie Ursache oder Wirkung der veränderten Lichtungs- und Wanddickenverhältnisse ist. Jedenfalls ist aber die Dickenzunahme der Gefäßinnenschichten mit $\mathrm{Th}$ o m a als eine Reaktion der Gefäßwand anzusehen, die imstande ist, einen Ausgleich für die Schwächung der Wand zu schaffen. Die physiologische diffuse Intimaverdickung im erwachsenen Körper ist schon als Analogie anzusehen. Eine wahre Hypertrophie der funktionell wichtigsten Schichten der Media kommt offenbar nur selten an der Aorta, häufiger dagegen an Pulmonalis und Renalis vor. So zu sagen als vikariierende Hypertrophien mit vielleicht ungenügendem funktionellem Effekte sind die Neubildungen von glatten Muskelfasern in Adventitia (Renalis und Iliaca communis) und Intima (Aorta) anzusehen.

10. Die Insuffizienz der Aortenklappen wirkt gewöhnlich nur auf den aufsteigenden Teil der Aorta, welcher erweitert und entsprechend verdünnt wird. Bei Schrumpfniere nimmt die Wanddicke der Aorta im allgemeinen zu.

\section{Literatur.}

1. Burke, Über angeborene Enge des Aortensystems. D. Arch. f. klin. Med. 1901, Bd. $71, \mathrm{~S} .189 .-2$. B. F is $\mathrm{ch}$ e $\mathrm{r}$ und $\mathrm{S} \mathrm{c} \mathrm{h} \mathrm{m}$ i e d e $\mathrm{n}$, Experimentelle Untersuchungen über 
die funktionelle Anpassung der Gefäßwand. Ztlbl. f. allg. Path. usw. 1908, Bd. 19, S. 936. 3. R ös sle, Ùber Hypertrophie und Organkorrelation. Münch. med. Wschr. 1908, Nr. 8. 4. Sch e e 1, Gefäßmessungen und Arteriosklerose. Virch. Arch. 1908, Bd. 191, S. 135. 5. S c hiele-Wiegand t Utber Wanddicke und Umfang der Arterien des menschlichen Körpers. Virch. Arch. 1880, Bd. 82, S. 27. - 6. S u te r, U̇ber das Verhalten des Aortenumfangs unter physiologischen und pathologischen Bedingungen. Arch. f. exper. Path. u. Ther. 1897, Bd. 39, S. 289. - 7. T h o r e 1, Pathologie der Kreislauforgane. Lubarsch-Ostertag, Ergebn. d. allg. Path. u. path. Anat. 1903, I, S. 936, 9. Jhrg. - 8. T h o r e l, Pathologie der Kreislauforgane. Lubarsch-Ostertag, Ergebn. d. allg. Path. u. path. Anat. 1907, II, S. 458, 11. Jhrg.

\section{V. \\ Zur Analyse der Entstehungsbedingungen der Thromben und Lebernekrosen nach intravenöser Injektion von $\ddot{A ̈ t h e r}^{1}$ )}

(Aus dem Laboratorium für experimentelle Pathologie der University of Pennsylvania, Philadelphia.)

Von

Le o L o e b und Milton K. Meyers.

Wenn wir im folgenden über Versuche berichten, welche die Analyse der im Gefolge von intravenösen Injektionen von Äther auftretenden Thromben und Lebernekrosen bezwecken, so soll der Äther als Repräsentant der hämolytisch wirkenden Substanzen dienen. Die hier erhaltenen Befunde mögen vielleicht auch für das Verständnis von unter anderen Umständen gefundenen Thromben und Gewebsnekrosen von einigem Werte sein.

Hierzu kommt aber, daß die in der Literatur vorliegenden Angaben über die Wirkung des Äthers nach intravenöser Injektion, soweit sie sich auf Thrombose und Gewebsnekrose beziehen, widerspruchsvoll sind.

So gibt $\mathrm{Naunyn}{ }^{2}$ ) an, daß Ätherinjektionen in eine Mesenterialvene intravaskuläre Blutgerinnung zur Folge haben. H a $\mathbf{~ a ~ u}^{3}$ ) anf der andern Seite berichtet über die Bildung von weißen Herzthromben nach Injektion von Ather in die Ohrvene des Kaninchens. As c h of $\mathrm{f}^{4}$ ) spricht die Ansicht aus, daß Äther keine echte Gerinnung bewirkt, sondern nur das Bluteiweiß präzipitiert. Auch $\mathrm{Flex} n$ e $\mathrm{r}^{5}$ ) glaubt nicht, daß intravenöse Injektion von X̊ther zur Fibrinbildung führt, wohl aber die Agglutination der Erythrozyten, und daher die Bildung echter Agglutinationsthromben zur Folge hat. Wir sehen also, daß die Mehrzahl der Autoren annimmt,

1) Schon früher berichtete der eine von uns über einen Teil dieser Versuche (University of Pennsylvania Medical Bulletin 1906). Seitdem wurden die Untersuchungen fortgesetzt, und hier soll ein zusammenfassender Bericht über die Ergebnisse erstattet werden.

2) Untersuchungen über Blutgerinnung im lebenden Tiere und ihre Folgen. Arch. f. exp. Path. u. Pharm. 1873 Bd. 1.

${ }^{3}$ ) Die Entstehung und Zusammensetzung der Thromben. Vorl. Mitteilung, Fortschr. d. Med. 1886 Bd. 4.

4) Utber den Aufbau der menschlichen Thromben und das Vorkommen von Plättchen in den blutbildenden Organen. Virch. Arch. 1892 Bd. 130.

$\left.{ }^{5}\right)$ On Thrombi composed of agglutinated red Bloodcorpuscles. Prelim. commun. Journ. of Med. Research. 1902 vol. 8. 